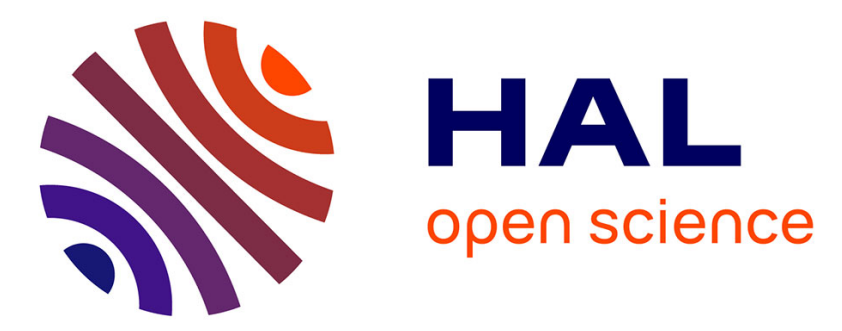

\title{
An experimental investigation of the response of slender protective structures to rockfall impacts
}

Stéphane Lambert, Franck Bourrier, P. Gotteland, François Nicot

\section{To cite this version:}

Stéphane Lambert, Franck Bourrier, P. Gotteland, François Nicot. An experimental investigation of the response of slender protective structures to rockfall impacts. Canadian Geotechnical Journal, inPress, 57 (8), pp.1215-1231. 10.1139/cgj-2019-0147 . hal-02609863

\section{HAL Id: hal-02609863 \\ https: / hal.inrae.fr/hal-02609863}

Submitted on 14 Sep 2021

HAL is a multi-disciplinary open access archive for the deposit and dissemination of scientific research documents, whether they are published or not. The documents may come from teaching and research institutions in France or abroad, or from public or private research centers.
L'archive ouverte pluridisciplinaire HAL, est destinée au dépôt et à la diffusion de documents scientifiques de niveau recherche, publiés ou non, émanant des établissements d'enseignement et de recherche français ou étrangers, des laboratoires publics ou privés.

\section{(c)(1)}

Distributed under a Creative Commons Attribution| 4.0 International License 


\title{
An experimental investigation of the response of slender protective structures to rockfall impacts
}

\author{
Stéphane Lambert, Frank Bourrier, Philippe Gotteland, and François Nicot
}

\begin{abstract}
This article investigates the mechanical response of slender rockfall protection embankments subjected to impacts based on real-scale experiments. More specifically, it deals with rectangular (in cross-section) vertical-sided gabion structures, designed to meet footprint constraints. These three-layered structures, $3 \mathrm{~m}$ in width and $4 \mathrm{~m}$ in height, are made up of gabion cages filled with different materials, depending on their location in the structure. Real-scale experiments were conducted with impact energies up to about $2000 \mathrm{~kJ}$ on two structures differing by the fill material used for their middle layer: ballast or sand-tire mixture. The experiments demonstrate the capacity of these slender structures in resisting high-energy impacts. The response of the structures is also addressed considering data obtained using different measuring techniques and a large number of sensors within the structure. The results are presented and discussed with the aim of highlighting some issues associated with the structure impact response, such as the load lateral diffusion, stone breakage, the contribution of the wire mesh, and the fill material characteristics. In the end, a structure with a middle layer filled with ballast appears more efficient in reducing the structure back face displacement.
\end{abstract}

Key words: rockfall, embankment, gabion, structure design, impact, plastic deformation.

Résumé : Cet article étudie la réponse mécanique des talus minces de protection contre les chutes de pierres soumis à des impacts à partir d'expériences en grandeur réelle. Plus spécifiquement, il s'agit de structures rectangulaires (en section transversale) à parements verticaux et constituées de gabions conçues pour réduire leur emprise au sol. Ces structures à trois couches, d'une largeur de $3 \mathrm{~m}$ e td'une hauteur de $4 \mathrm{~m}$, sont constituées de cages à gabions remplies de différents matériaux, selon leur emplacement dans la structure. Des expériences en grandeur réelle ont été menées avec des énergies d'impact allant jusqu'à environ $2000 \mathrm{~kJ}$ sur deux structures différentes par le matériau de remplissage utilisé pour leur couche intermédiaire : ballast ou mélange sable-pneu. Les expériences démontrent la capacité de ces structures minces à résister aux impacts à haute énergie. La réponse des structures est également abordée en tenant compte des données obtenues à l'aide de différentes techniques de mesure et d'un grand nombre de capteurs dans la structure. Les résultats sont présentés et discutés pour aborder certaines questions liées à la réponse à l'impact de la structure telles que la diffusion latérale de la charge, la fracturation des pierres, la contribution de l'enveloppe grillagée et les caractéristiques du matériau de remplissage. En fin de compte, une structure avec une couche intermédiaire remplie de ballast semble plus efficace pour réduire le déplacement de la face arrière de la structure

Mots-clés : éboulement, remblai, gabion, conception de la structure, impact, déformation plastique.

\section{Introduction}

Protection against rockfall may be achieved by civil engineering structures built perpendicular to the slope, such as embankments, fences, or concrete barriers. For these structure types, one constraint is related to the space occupied by the structure itself and the additional space required for its normal operation. This footprint constraint is particularly strong when dealing with transportation corridors at the toe of steep slopes or in narrow valleys. The normal operation of flexible fences relates to their maximal extension during the rock block interception, sometimes exceeding $6 \mathrm{~m}$. As for embankments, the normal operation often requires a ditch with a $5 \mathrm{~m}$ typical width for collecting blocks (Fig. 1; Lambert and Kister 2017b). For these latter structures, the main footprint-related issue is its foundation width, because embankments are massive earthworks from 3 to $25 \mathrm{~m}$ high (Lambert and Bourrier 2013; Lambert and Kister 2018). The other limitation with embankments, in particular over fences, is the large volume of building materials, which is critical where the natural slope is not stable or where the onsite materials are not suitable for this aim (e.g., Simmons et al. 2009; Lorentz et al. 2010). In this context, optimizing rockfall protection embankments with the aim of reducing their volume and footprint is a challenging issue. This was addressed in the framework of the research project REMPARe, considering gabion structures to serve as rockfall protection embankments.

This article investigates the mechanical response to impact of two-sided gabion walls to serve as rockfall protection embankments. Gabion cages allow building slender rockfall protection embankments, with vertical faces, constituting space efficient impact barriers to incoming rock blocks. In addition, it is possible to create structures with improved impact strength by filling the gabion cages with materials with particular characteristics, depending on their position in the structure (Lambert et al. 2009, 2014). 
Fig. 1. Two classical rockfall protection embankments in (a) Switzerland and (b) France (@ S. Lambert). [Colour online.]

(a)

(b)
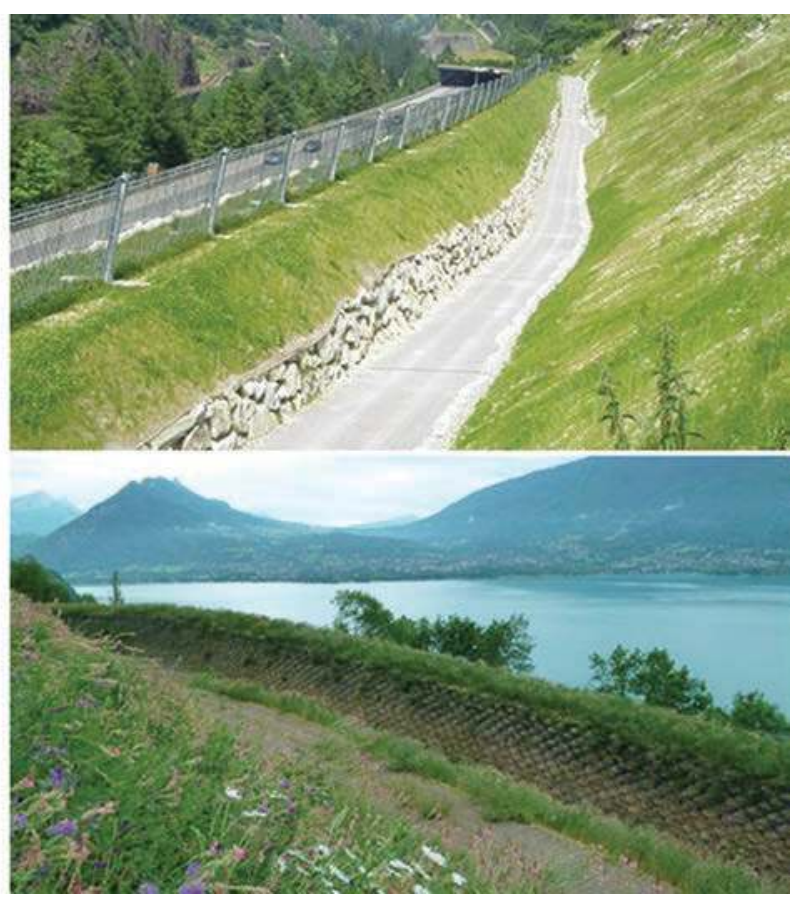

The localized impact response of gabion structures has been investigated experimentally by different authors to develop structures used as roadside impact absorption devices (Amato et al. 2015), debris flow impact attenuator (Ng et al. 2016, 2018), and rockfall protection embankments (Heymann et al. 2010; Lambert et al. 2009, 2014). The experiments aimed at evaluating the gabion structure response to impact, in particular focusing on their ability in damping the impact force and limiting the transmitted force. The studies differ by the gabion fill materials, structure dimensions, and boundary conditions, as well as rock block incident kinetic energy. Some of these experiments in particular addressed the influence of the fill material characteristics (Heymann et al. 2010; Amato et al. 2015; $\mathrm{Ng}$ et al. 2018) or repetition of impacts (Heymann et al. 2010; Ng et al. 2016, 2018; Su et al. 2018). Granular fill material characteristics with influence on the impact response of gabion structures, in terms of impact force or transmitted force, include initial compaction, unit mass, and coarse fill material crushability. Numerical simulations have confirmed the strong influence of the fill material modulus and grain size distribution on the transmitted force in the case of gabion structures leaned against a rigid wall (Bourrier et al. 2011; Su et al. 2019).

As for rockfall protection embankments, various real-scale impact experiments have been conducted over the last two decades and considered different types of embankments and impact energies (see lists in Lambert and Bourrier 2013 and Lambert and Kister 2017a). Nevertheless, for cost reasons, the test configurations do not cover the wide variety of energy ranges and existing structure types. These experiments provided very limited data related to the embankment response during the impact, while this would be of great value when developing numerical models of these structures, as those presented in Ronco et al. (2009) and Breugnot et al. (2015). For these reasons, any new set of data related to the realtime impact response of embankments is of great value for improving design methods and developing numerical models for these structures.

In a previous article, the authors have presented real-scale experiments conducted on a two-layered gabion wall leaned against a levee (Lambert et al. 2014). The structure was impacted in its center by a spherical projectile $6500 \mathrm{~kg}$ in mass and traveling along a cableway with a maximum velocity of $28 \mathrm{~m} / \mathrm{s}$. Three main conclusions were drawn concerning the influence of the constitutive materials on the structure response to impact. Crushing of the coarse materials comprising the front face gabions dissipates energy and attenuates the load applied to the second vertical layer of gabions. The sand-tire mixture exhibits elasticity that allows the second layer of the sandwich to recover its initial geometrical configuration after impact. The wire netting distributes the load within the structure, while facilitating the post-impact structure repair. Such layered-gabion structure thus combines advantages from their composite nature, stemming from the interaction between the gabion cages and their fill materials, with advantages derived from their sandwich nature, by the use of different fill materials for the interconnected vertical layers.

In this article, the impact response of two freestanding gabion structures is investigated considering similar building materials and testing conditions as that in Lambert et al. (2014). The structures are rectangular in vertical cross-section, $3 \mathrm{~m}$ in width and $4 \mathrm{~m}$ in height, and consist of three vertical layers of interconnected gabion cages filled with different materials. The difference between the two tested structures lies in the fill material used for the middle layer, which is either ballast or a sand-tire mixture. For both structures, the gabions forming the first and third layers, at the front and back faces, are filled with a crushed quarry limestone. These structures were subjected to three successive impacts in the center of the front face by a spherical projectile with a kinetic energy up to about $2000 \mathrm{~kJ}$. The structures were instrumented with accelerometers and displacement sensors for investigating their real-time response. The analysis of the various set of collected data provides a sound basis to validate the use of such structures for rockfall protection purpose while placing an emphasis on the detailed description of their mechanical response to an extent rarely seen before.

The article is structured as follows. First, the experiments are introduced, describing the measuring techniques and discussing their limits in such a context. Then the impact response of these structures is addressed, first considering the structure with a middle layer made of ballast and, second, considering the other structure. In this purpose, the acceleration of the projectile, the acceleration and displacements measured in different points within the structure, and the external deformation of the structures are successively accounted for. The results are presented and discussed in particular with the aim of highlighting some trends and mechanisms observed and that are considered as having an influence on the structure impact response.

\section{Structures and experiments}

\subsection{Impacted structures}

The two structures were rectangular in cross-section, $8 \mathrm{~m}$ long, $4 \mathrm{~m}$ high, and $3 \mathrm{~m}$ wide, and consisted of piled-up and interconnected gabion cages, arranged in three vertical layers (Fig. 2). The slenderness ratio (i.e., the ratio between the structure height and width) of these structures is thus 1.3 , which is very high compared with more classical rockfall protection embankments. For example, data from Lambert and Kister (2017b) suggest a mean slenderness ratio of $\sim 0.5$ for existing embankments, with a $0.3-0.8$ typical range. Widely used gabion cages were considered for the experiments. These were made from $2.7 \mathrm{~mm}$ diameter wires, woven to create an hexagonal mesh with $80 \mathrm{~mm} \times 120 \mathrm{~mm}$ openings. The gabions were parallelepiped in shape, 3 or $2 \mathrm{~m}$ long, subdivided into three or two $1 \mathrm{~m}^{3}$ cubic cells, respectively. Each of the three layers of the structure is thus constituted with 24 cubic cells.

For both structures, the front face gabions, exposed to impact, as well as the back face gabions were filled with a crushed quarry limestone, with an angular shape and $80-120 \mathrm{~mm}$ grain size. This filling material was considered for aesthetic reasons and excellent 
Fig. 2. (a) Vertical and (b) horizontal structure cross-sections. [Colour online.]

(a)

a)
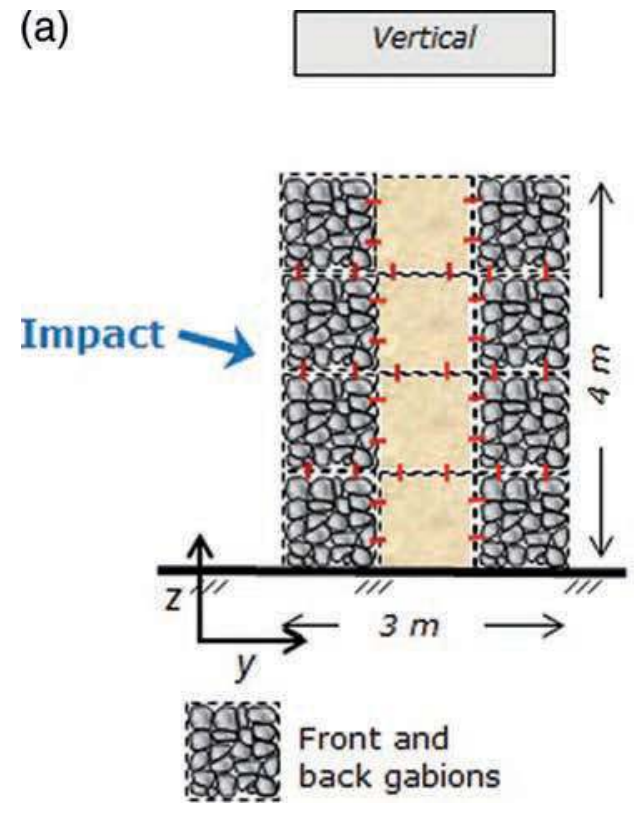

(b)
Horizontal

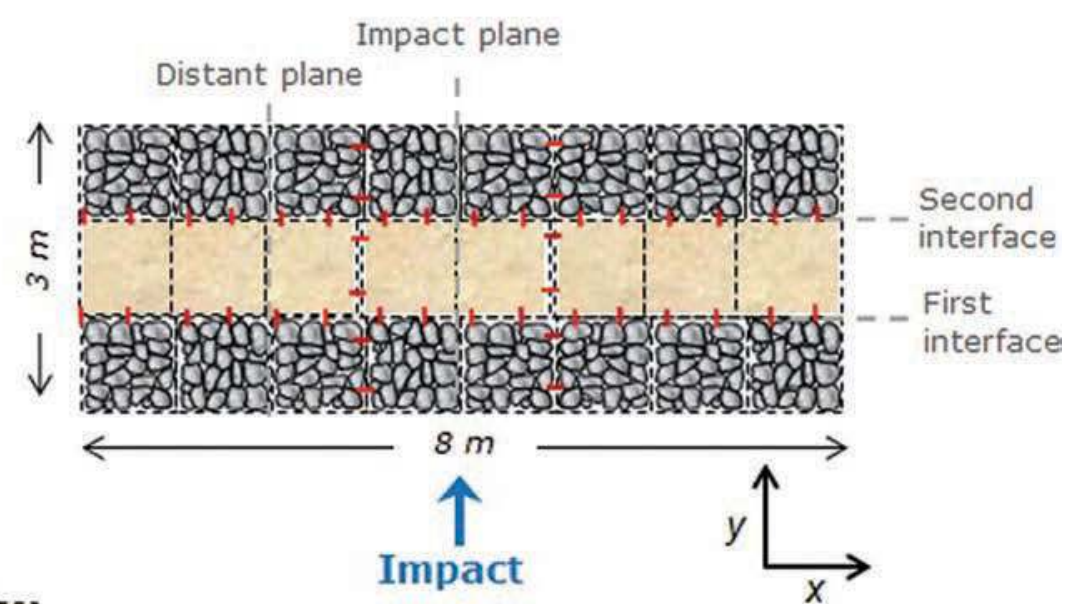

I Connection staples durability vs. climatic agents, in particular. In addition, this material has been shown to limit both the impact force and the force transmitted within the structure due to stones crushing (Lambert et al. 2009).

The two tested structures differed by the fill material used for the gabions forming the structure middle layer. In accordance with the objectives of the REMPARe project, the two filling materials were considered first for waste recycling purposes. These materials were ballast resulting from the maintenance of old railways and shredded tires, obtained from processed end-of-life vehicles tires. This latter material was mixed with sand, containing $30 \%$ by mass of tires, both for reducing fire risk and for mechanical characteristics improvement (Zornberg et al. 2004). In particular, previous research suggested that, depending on the contexts and conditions, sand-tire mixtures can attenuate dynamic loadings (Lee and Roh 2007). It is noticeable that no adverse effect to the environment was observed with this recycled material when used in embankments (Hennebert et al. 2014).

The aim with these materials was to derive benefits from their particular characteristics in relation to each other, in view of optimizing the structure impact response following two opposite strategies. On one side, ballast was expected to increase the structure inertia, due its higher unit mass, while being more rigid. On the other, the sand-tire mixture was expected to favor energy dissipation by allowing large deformation while inducing a certain structure geometry recovery after impact, due to elasticity (Lambert et al. 2009). These two materials were thus expected to give the structure different global characteristics when used as middle layer fill material.

Table 1 lists some characteristics of the fill materials. The tire pieces had no particular shape. The cohesion and friction angle were obtained from direct shear tests conducted on a large shear box over the $50-150 \mathrm{kPa}$ normal stress range, which was defined considering the application case. Considering these test conditions, the provided cohesion value should only be considered as a result of the curve-fitting. The shear tests on the sand-tire mixture revealed the absence of peak in the stress-strain curve. Because of this well-known characteristic of some mixtures of sand with tire shreds (Edeskär 2004), the friction angle and cohesion were computed from the shear stress value measured at a strain of $15 \%$. Unit mass of gabions filled with the different materials are indicative because uncertainty associated with the gabion cages volume, as well as filling method reproducibility made more accurate unit mass measurement impossible.

The railway ballast was used as fill for the middle layer of the first structure while the sand-tire mixture was used for the second structure. In the following, the two structures are referred to as BA and STM depending on their middle layer gabions fill material: ballast and sand-tire mixture, respectively.

The middle layer fill materials, being smaller than the mesh size, were contained in the gabion cages by a nonwoven, needlepunched geotextile. There is no durability issue related to this material, as it is covered in this type of structure.

The two structures were built as done on actual worksites, for what concerns gabion installation, connection as well as filling. For more details see Lambert et al. (2014). In the following, the interfaces between the front face gabions and the middle layer gabions and that between the middle layer gabions and the back face gabions are referred to as first and second interfaces, respectively.

\subsection{Impact experiments}

The impact was generated by a $1.6 \mathrm{~m}$ diameter and $6500 \mathrm{~kg}$ sphere (Fig. 3). This projectile was made from a steel shell filled with concrete with an inside space left so that accelerometers can be placed at the sphere mass center. A cableway conveyed the sphere until it impacted the structure. The sphere was suspended by a cable sling connected to a trolley, freely travelling along the inclined cableway. This system allowed generating impact relevant to rockfall impacts, with a maximum translational velocity of $28 \mathrm{~m} / \mathrm{s}$ and a downward incident trajectory in the 16-28 degree range. The impact energy was varied by adapting the trolley departing point. The length of the cable sling and the tension of the cableway were adjusted so that impact occurred at structure midheight approximately. The sphere remained hanged to the cableway during the whole experiment duration. As the trolley still moved along the cableway after impact, a wood pile was placed on top of the structure to prevent damages to the gabion cages on top of the structure as a result of an excessive cable sling penetration (Fig. 3a).

Structures BA and STM were exposed to three successive impacts with translational kinetic energies of around 200,500, and $2000 \mathrm{~kJ}$ at impact. The test sequence was defined, based on the feedback from the experiments presented in Lambert et al. (2014), 
Table 1. Characteristics of the fill materials of the two middle layers.

\begin{tabular}{llll}
\hline & Limestone & Ballast & Tire-sand mixture \\
\hline Grain-size distribution $(\mathrm{mm})$ & $80-120$ & $20-50$ & Sand: 0-4; tire: 20-150 \\
Friction angle $\left({ }^{\circ}\right)$ & - & 53.5 & 20 \\
Cohesion $(\mathrm{kPa})$ & - & 65 & 0 \\
Gabion unit mass $\left(\mathrm{kg} / \mathrm{m}^{3}\right)$ & 1600 & 1700 & 1400 \\
\hline
\end{tabular}

Note: A dash (-) indicates data not determined.

Fig. 3. (a) Uphill face and (b) side views of structure STM (i.e., sand-tire mixture) showing the projectile hanged up on the cableway. The wood pile and the ducts respectively protecting the uphill face top and the sensor cables are also visible. [Colour online.]
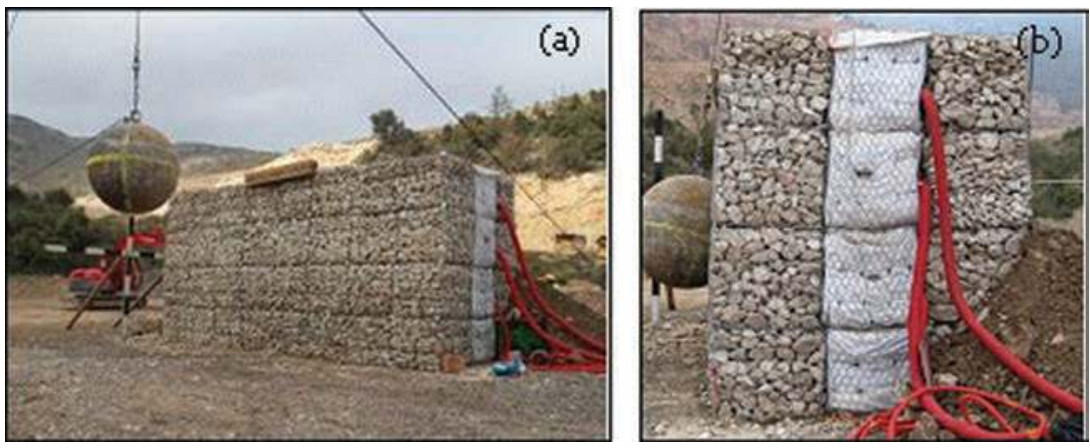

in view of getting as much data as possible at different energy levels on the same structure while limiting expensive structure repair. As will be discussed, the $500 \mathrm{~kJ}$ impact test required moderate repair. The $2000 \mathrm{~kJ}$ impact test aimed at approaching the structures capacity. This kinetic energy was also the maximum the system was able to generate. The impact height and velocity as well as the incident angle were determined from high-speed camera images, when available (Table 2). Missing data in this table result from image acquisition and treatment issues. The variability in the impact heights and incident angles from one test to the other, as well as the difference in measured kinetic energy compared with the targeted one, result from the difficulty in having a precise control of the impact conditions while using a projectile conveyed by a cableway.

No repair was done after the first impacts, as damage was limited with minor front face penetration. On the contrary, repair of the facing of both structures was necessary after the second impact $(500 \mathrm{~kJ})$ due to major deformation and damage. It consisted in placing a wire netting panel with dimensions much larger than the deformed area. It was attached on the front face and backfilled with the crushed quarry limestone. This mode of repair was considered a simple and efficient way to restore the embankment global characteristics and external appearance. It was preferred for cost reasons over impacted gabion replacement, as described in Lambert et al. (2014). However, the mechanical characteristics of the structure in the vicinity of the impacted area were slightly changed. The results presented in the following sections clearly reveal that after the $500 \mathrm{~kJ}$ impact test, gabion cage deformation is observed within the structure as well as crushing of the front layer fill material. The influence of these changes on the structure response to subsequent impacts cannot be ignored but it is not quantified.

\subsection{Instrumentation}

A large number of measurement devices were used to raise the mechanical response of these structures under impact loading with the aim of evaluating the kinematical features (internal strains, global displacements) and addressing the impact-induced stress propagation issue. Measurements were either static (preand post-impact) or real-time and were either made outside or within the structure. Measuring points were located in two vertical planes across the structure, one in the impact direction and the other $2 \mathrm{~m}$ aside (Fig. $2 b$ ). More precisely, these points were
Table 2. Impact conditions for the two structures.

\begin{tabular}{llllc}
\hline Test ID & $\begin{array}{l}\text { Velocity } \\
(\mathrm{m} / \mathrm{s})\end{array}$ & $\begin{array}{l}\text { Incident } \\
\text { angle }\left({ }^{\circ}\right)\end{array}$ & $\begin{array}{l}\text { Impact } \\
\text { height }(\mathrm{m})\end{array}$ & $\begin{array}{l}\text { Kinetic } \\
\text { energy }(\mathrm{kJ})\end{array}$ \\
\hline BA-1 & - & - & - & $200^{*}$ \\
BA-2 & 13 & 28 & 2 & 530 \\
BA-3 & - & - & - & $2000^{*}$ \\
STM-1 & 8 & 16 & 1.9 & 180 \\
STM-2 & 13 & 26 & 1.8 & 590 \\
STM-3 & 26 & 25 & 1.7 & 2180 \\
\hline
\end{tabular}

Note: BA, ballast fill structure; STM, sand-tire mixture structure. An asterisk (*) refers to a targeted value; a dash $(-)$ indicates data not available.

located on the back face, on the first and second interfaces and in the middle of the middle layer. The adopted approach for the instrumentation was similar to that in Lambert et al. (2014).

The projectile kinematics was tracked by a high-speed camera, at a rate of 250 frames per second, and an embedded triaxial capacitive accelerometer with a 200 g capacity, giving access to the projectile incident velocity and inclination, impact height position, and deceleration with time. The embankment was equipped with piezo-resistive accelerometers, with measuring ranges from $100 \mathrm{~g}$ to $200 \mathrm{~g}$ depending on the distance to the impacted area. The piezo-resistive technology was preferred over the piezo-electric one based on tests in similar conditions that revealed that the latter technology resulted in a signal offset, emerging about $20 \mathrm{~ms}$ after the impact beginning (Heymann et al. 2010; Heymann 2012). This bias was attributed to the loading duration and sensor bandwidth. The accelerometers were protected from direct impact by a rigid cap and placed on rigid PVC supports attached to the wire mesh. The signals from all the accelerometer were synchronously collected via a data logger at a $10 \mathrm{kHz}$ frequency. The displacement of specific points within the structure was measured using linear position transducers with a $1000 \mathrm{~mm}$ stroke, supported by vertical posts located $3 \mathrm{~m}$ from the back face. Extension rods passing through part of the structure connected the sensors to the measurement points.

The structure geometry changes were monitored conducting topographical surveys before and after each impact with a precision much better than $5 \mathrm{~mm}$. In this aim, targets were fixed on the wire mesh of the front and back faces, with a spatial spacing of 0.5 or $1 \mathrm{~m}$ depending on the distance to the impact point. 
Fig. 4. Deformation of displacement sensor extension rods after the third impact on structure BA (i.e., ballast). [Colour online.]

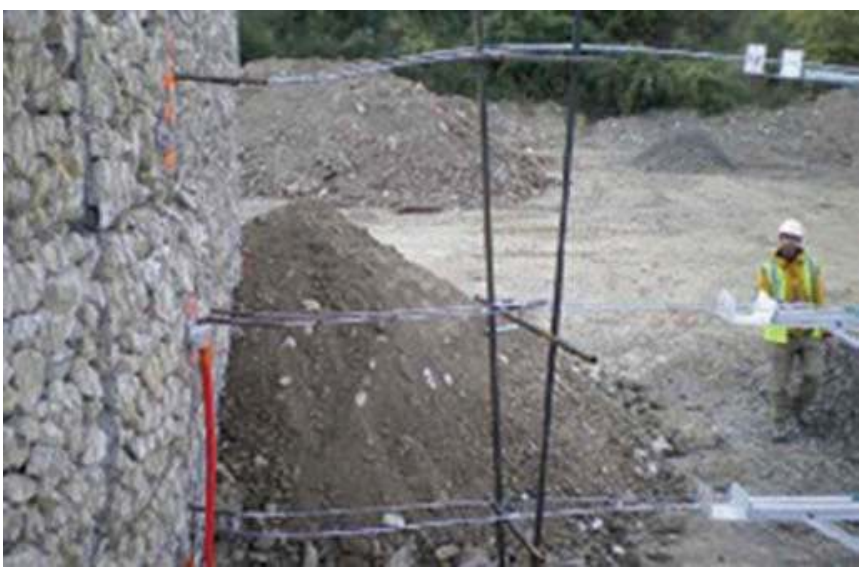

The displacements obtained from the displacement sensors, the high-speed camera images, the topographical survey, and those deduced from the accelerometers were compared to test the correctness of the measurements and relevancy of these techniques. Some limitations arose as illustrated in the following. The technique of using high-speed camera images faced no specific problem for this application and allowed tracking the projectile displacement with time with a precision mainly depending on the image resolution, distance to the scene, and natural light intensity. It is worth noting that the $20 \mathrm{~m}$ distant camera experienced little lateral oscillations due to impact-induced vibrations transmitted by the ground. This had no consequence on the data usefulness, as it occurred after the projectile was stopped.

The impact beginning was defined from the time the projectile acceleration experienced large increase compared with the signal noise. All the collected signals were corrected from their preimpact offset. Accelerations were filtered with a moving $0.005 \mathrm{~s}$ running average filter. This very simple filtering method was preferred over more complex methods because of the difference in frequency content of the measured signals, depending on the accelerometer location and surrounding material in the structure. No filter was applied on the displacement sensors measurements.

Displacement sensors connected to extension rods entering the structure provided reliable real-time measurements during the first impact, but progressively faced the problem of structure displacement with successive impacts, inducing deformation of the rods, which in turn affected the measurement by the sensor (Fig. 4). Because of this bias, displacement measurements during the third impact test should be considered and interpreted with caution. The topographical survey was highly relevant and useful for measuring the post-impact displacement on all the faces of the structures, in any direction, which was inaccessible with other techniques. The accuracy of the measurements was not altered by this specific context of use. Nevertheless, in the impacted area and during the third impact, this technique faced the problem of large front face reverse displacement and partial fill material collapse after the projectile was removed. It was thus not possible to measure the post-impact crater in these cases. Nevertheless, this technique was used to measure the position at rest of the projectile while embedded in the structure.

The method consisting in deriving the displacement from the acceleration measurements by double integration revealed to be inappropriate in some cases. As for the projectile, comparison with the displacement obtained from the videos and that from post-impact measurements showed that the double integration underestimates the penetration by up to $25 \%$ for some tests. As for accelerometers within the structure, bad precision in the derived displacement was attributed to high energy impacts, type of support or surrounding media (fill material, wire mesh), and long-lasting acceleration. Displacements based on acceleration measurements may thus be unreliable, and direct measurements from videos or displacement sensors are recommended. Consistency between results from different sensor types allowed giving confidence in the collected data in view of their interpretation.

This context of use is rather specific and aggressive to the sensors. Measuring the kinematics of a structure made up of coarse granular materials and experiencing large displacement and strain is challenging. For instance, in spite of the precautions taken for their installation, some accelerometers and their wires were damaged during the test series on the structures. Tension in wires due to large and non-uniform displacements within the structure resulted in absence of signal or excessive noise, making the signal not exploitable. Also, some sensors were damaged due to shocks with stones, leading to acceleration in excess with respect to the sensors limit capacities. It was not possible to repair or replace these sensors and cables during the test series. Finally, some accelerometers within the structure showed signals with high-amplitude oscillations, certainly in relation with the materials in contact. Therefore, only a fraction of the installed accelerometers provided data for all the tests, restricting comparison from one impact case to the other. This limitation guides the results presentation in the following section.

\section{Structure impact response}

The impact response of the structures is first addressed for both structures BA and STM considering measurements and observations at the structure. The real-time impact response of structure BA is addressed based on acceleration measurements made within the structure. The response of the second structure, STM, is addressed by comparison with that of structure BA, focusing on measurements made within the middle layer, which differed from one structure to the other. Then, topographical and displacement sensors measurements are presented and discussed.

For all the plotted curves, $t=0$ corresponds to the impact beginning. The time window considered for plotting the accelerations measured within the structure was set to $0-0.15 \mathrm{~s}$ to focus on the period of time during which the wave travels through the structure, from the impacted area.

\subsection{Visual observations}

Both BA and STM structures succeeded in stopping the three impacts up to $2000 \mathrm{~kJ}$ in kinetic energy without collapsing. Impacts resulted in deformation and damage, which increased with the impact energy. The main visible change after the first impacts was a spherical crater in the impacted area, with moderate depth. No other change was clearly visible, except a few cases of stone breakage in the impacted area. Increasing the impact energy up to $500 \mathrm{~kJ}$ led to higher face deformation and damage, in terms of penetration and stones breakage. In addition, a few metal wires were cut in the impacted area. Deformation of the whole structure along its longitudinal axis together with displacement of the back face were also observed (Fig. $5 b$ ).

The $2000 \mathrm{~kJ}$ impacts led to much more deformation and damage to the structures. In the impacted area, stone crushing was generalized and gabion cages were torn open, resulting in gravitydriven dump of the fill material after projectile removal (Fig. 6c). The back face post-impact displacement was substantial, combining outward translation and settlement of the gabion cages in the middle section (Figs. $6 b$ and $6 d$ ). During the impact tests, an uplift of the crest above the impacted area was clearly observed.

Some open staples were observed after the last tests, between gabion cages on the back face, revealing that high tensile loads developed in the wire mesh panels on this face. This is to be set against video showing that the back face experienced very large displacement followed by a reverse displacement. 
Fig. 5. The $500 \mathrm{~kJ}$ impact resulted in (a) a large crater on the uphill face and $(b)$ structure deformation along its transverse axis (illustration for structure BA). [Colour online.]
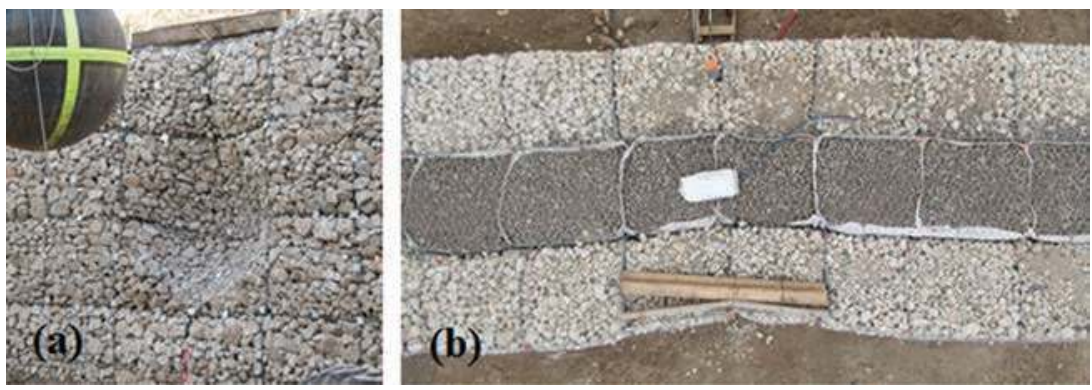

Fig. 6. Views of $(a, c)$ the uphill face and crest and $(d, b)$ the downhill face of structures $(a, b)$ BA and $(c, d)$ STM after the $2000 \mathrm{~kJ}$ kinetic energy impact test. [Colour online.]
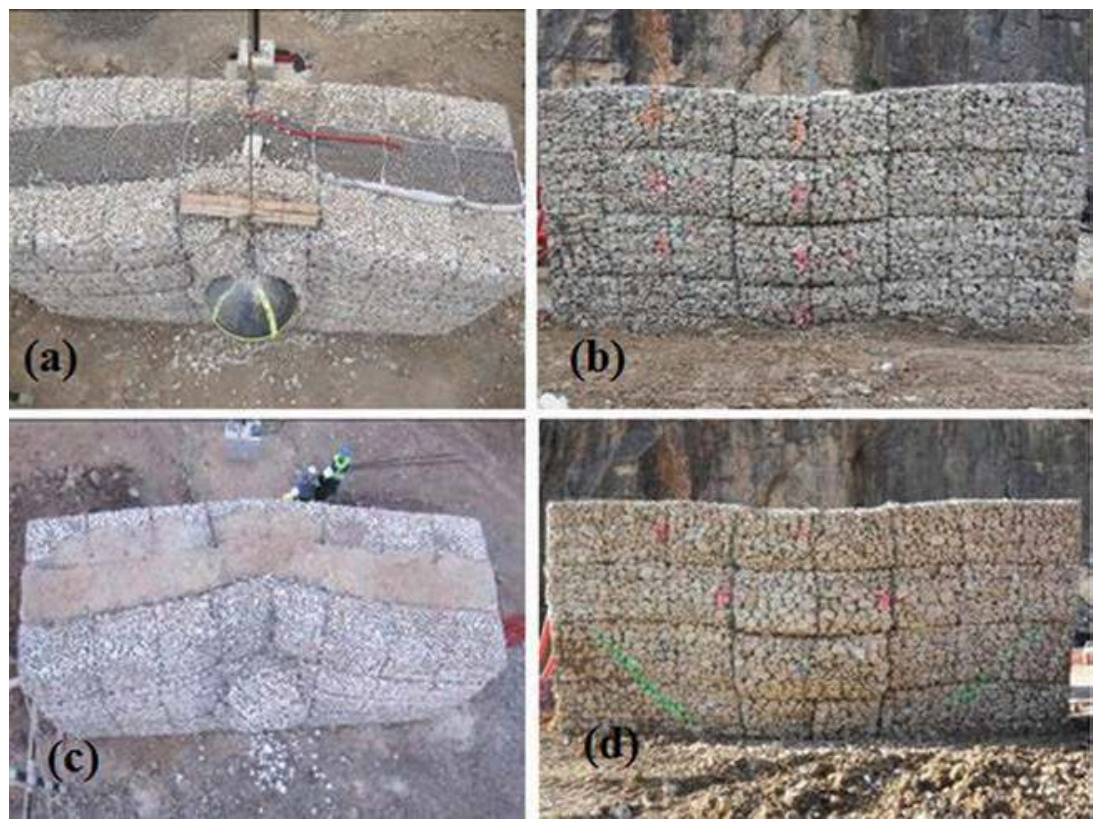

All these observations concern both BA and STM structures, with slight differences in amplitude from one structure to the other. It is worth noting that none of the tests resulted in basal sliding.

\subsection{Impact loading}

Figure 7 shows the projectile acceleration recorded during the impact tests, except for test STM-3 due to a sensor fault during impact. The impact beginning, and thus reference time for all curves $(t=0)$, was defined from these measurements.

The amplitude and shape of the curves obtained for the first two impact energies were very similar from one structure to the other, suggesting that the curve for test STM-3 would have been similar to that of BA-3 if it had been recorded. Curves for the first impact exhibited no sharp peak but a quasi-plateau. This in particular contrasts with the very similar impact case presented by Lambert et al. (2014), where the $200 \mathrm{~kJ}$ impact test curve showed a sharp peak. This difference may be attributed to slight differences in stone arrangement at the front face. Comparison between the first and subsequent impact tests shows that the former lasted twice as long (typically $250 \mathrm{vs.} 120 \mathrm{~ms}$ ). This latter observation may be attributed to the difference in incident velocity. The penetration, and consequently the reaction force by the structure, increases much faster in case of a high-velocity projectile, resulting in a shorter duration for breaking the projectile velocity. Oscillations for tests 2 and 3 are considered as measurement bias and

should not be considered as representative of the impact loading. These oscillations are thought to result from the rapid displacement of the wire connecting the accelerometer, in the traveling projectile, to the data logger on the ground. The maximum acceleration increased logarithmically with the impact energy. For impacts at 200,500, and $2000 \mathrm{~kJ}$ these maximum were of about 70 , 600 , and $1300 \mathrm{~m} / \mathrm{s}^{2}$ resulting in impact forces of about 500,4000 , and $8500 \mathrm{kN}$, respectively. Giving a precise value for these maxima is not relevant, as they are highly dependent on the signal treatment, in terms of cutoff frequency in particular.

\subsection{Acceleration within the structure}

The impact generates a stress wave that propagates with time within the structure from the impacted area. A stress gradient propagates and locally generates acceleration. Measuring the acceleration within the structure is thus an indirect way to appreciate the stress variation with time and space. Accelerometers have been placed in different locations within the structure, for measuring the acceleration in various directions. Unfortunately, and as mentioned in Section 2.3, many data were missing or the collected signals could not be exploited due to excessive noise in particular. It was thus neither relevant nor possible to make an exhaustive presentation and comparison of all the data. Instead, measurements are presented with the aim of highlighting some phenomena related to the propagation of the stress wave within these particular slender freestanding structures. 
Fig. 7. Projectile acceleration recorded during the (a) $200 \mathrm{~kJ}$, (b) $500 \mathrm{~kJ}$, and (c) $2000 \mathrm{~kJ}$ impact tests on structures BA and STM. [Colour online.]
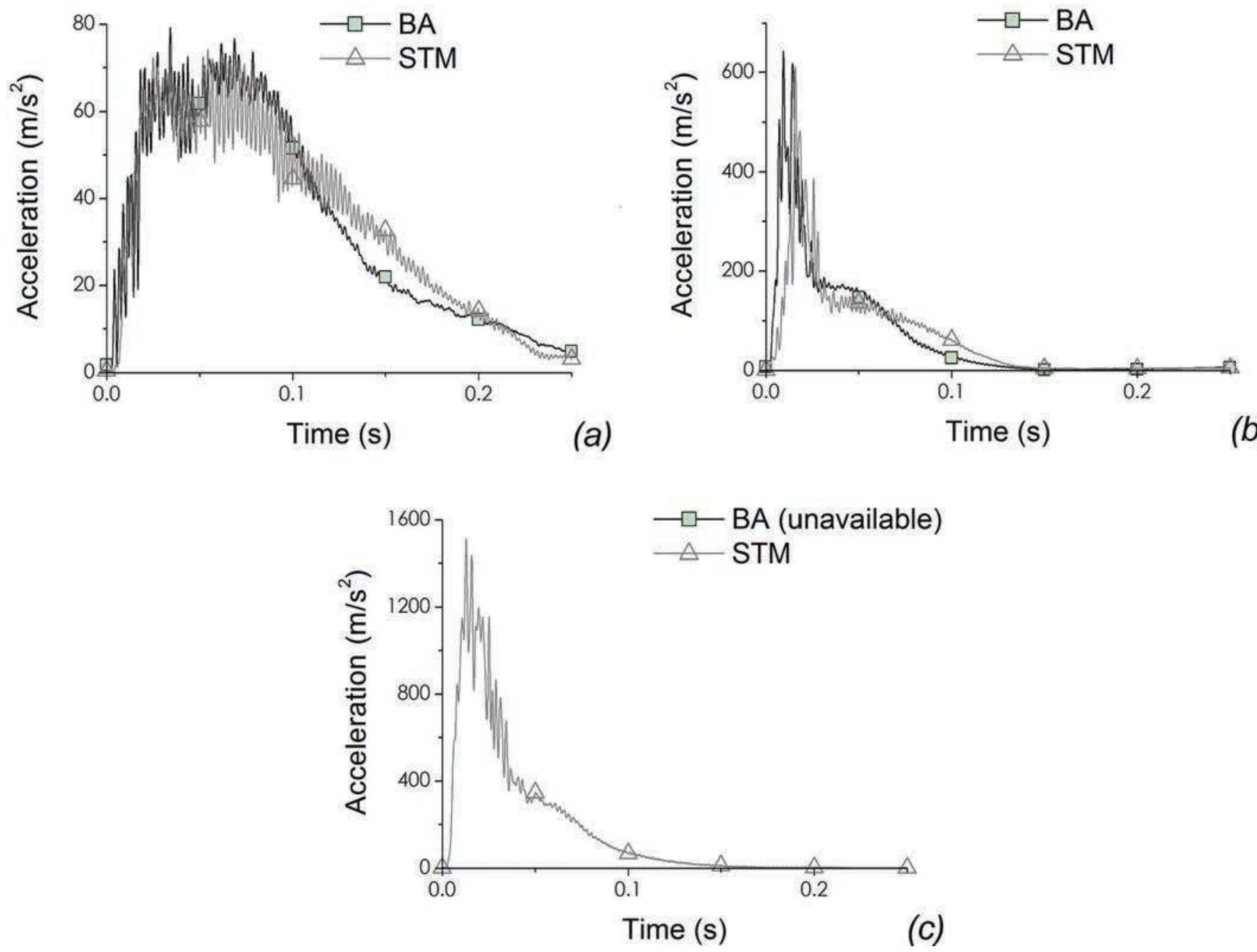

Focus is placed on the acceleration measured in the impact plane (i.e., the plane in the impact direction) and on the way the stress propagates in different directions, mainly based on structure BA experiments. A comparison with structure STM is then carried out focusing on measurements made in the middle layer.

\subsubsection{Stress wave propagation in the impact plane}

Figure 8 shows the acceleration measured along the $y$ axis in different points in the impact plane. For symmetry reasons, no acceleration measurement was made along the $x$ axis, corresponding to the longitudinal axis of the structure. The high-amplitude fluctuations observed during tests BA-3 for sensors placed on the back face were attributed to the displacement of the wire mesh to which the sensors were attached.

The amplitude of the acceleration at the first interface, between the face gabion layer and middle layer gabion layer, globally increased with the impact energy, from 200 to $\sim 400 \mathrm{~m} / \mathrm{s}^{2}$. This variation appeared to be small as compared with that of the impact energy ( 200 to $2200 \mathrm{~kJ}$ ) and that of the projectile acceleration (70 to $1400 \mathrm{~m} / \mathrm{s}^{2}$ ). In all three cases, the acceleration peak was reached about $25 \mathrm{~ms}$ after the impact beginning. Surprisingly and by contrast with the projectile acceleration, the first interface acceleration peak for test 2 was very close to that during impact test 1 . This is thought to be due to a different pattern of stress propagation within the structure resulting from the crater created during the first impact (Fig. 5a). Indeed, such a crater offers a larger contact surface to the projectile from the very impact be- ginning. The front face loaded surface being higher, the stress spreading in the structure is larger. The stress at the first interface, and consequently acceleration, is attenuated because of this higher spreading.

Figure 8 also reveals that for test 3 the back face higher acceleration was observed below the impact point, the green curve being above the blue one. A similar trend was mentioned in other studies concerning vertical gabion structures leaned against a rigid wall and exposed to normal-to-the-face impacts (Heymann 2012; Ng et al. 2016). In these cases, this trend was attributed to the increase in fill material density and consequently confining stress from the crest to the base. An additional explanation in the presented case could be the downward orientation of the projectile at impact.

Comparing curves plotted in Fig. 8 also reveals that the acceleration attenuation from the first interface to the back face decreased with the impact energy; the ratio of the maximum acceleration at the back face of the structure to that at the first interface increased from $10 \%$ during test 1 to $60 \%$ for test 3 . This reveals that test 1 induced substantial displacement at limited distance from the impacted area, while in test 3 there were substantial displacements in all the structure, due to higher impact energy. This is in line with the schematic description of the structure impact response proposed in Lambert and Bourrier (2013) and in Lambert and Kister (2018). By contrast, when comparing the back face acceleration (Fig. 8) with the projectile acceleration 
Fig. 8. Structure BA. Acceleration in the impact plane and along the $y$ axis at the first interface (point A) and on the downhill face (points B and C). Impact tests were at (a) $200 \mathrm{~kJ},(b) 500 \mathrm{~kJ}$, and (c) $2000 \mathrm{~kJ}$. [Colour online.]
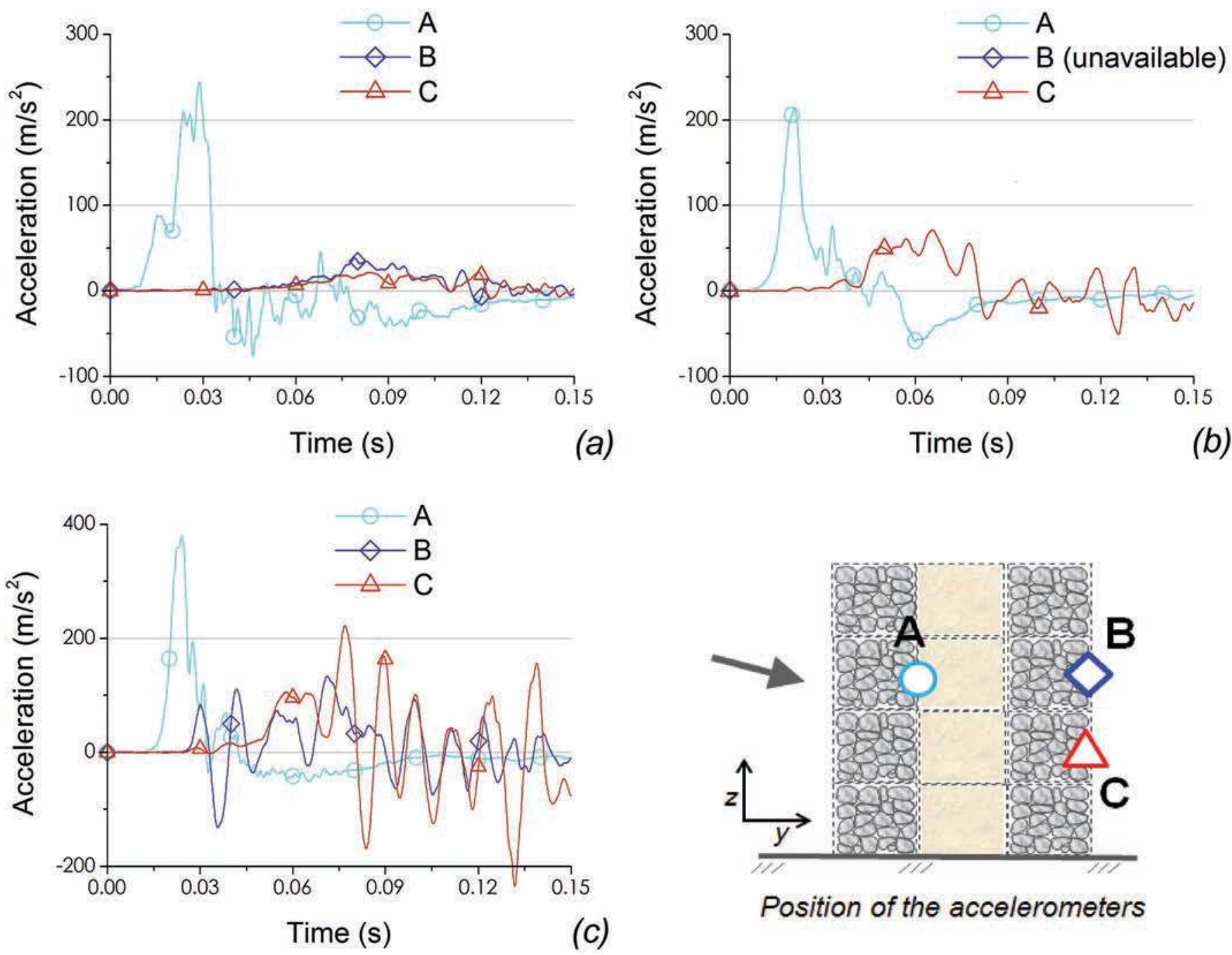

(Fig. 7), the opposite trend is observed; the ratio between peak values went from $50 \%$ for test 1 to $15 \%$ for test 3 .

When comparing the projectile acceleration (Fig. 7) with the acceleration at the first interface and at the back face of the structure (Fig. 8), it is observed that the increase in acceleration during the test series is much less within the structure. Indeed, the projectile acceleration peak is multiplied by 20 , from test 1 to test 3 , while it is multiplied by 2 and 6 , approximately, at the first interface and at the back face.

All these comments corroborate the idea that the projectile acceleration, and thus impact force, is not appropriate when investigating the impact response of such structures, in particular when considering the whole structure displacement (Lambert and Kister 2017a).

\subsubsection{Lateral diffusion}

To investigate the lateral diffusion of the stress, out of the impact plane, the acceleration measured in the distant plane at the second interface is shown in Fig. 9. The acceleration was measured at $3.5 \mathrm{~m}$ from the ground and along two axes ( $x$ and $y$ ). Along the $x$ axis, a first acceleration peak typically lasting $30 \mathrm{~ms}$ is observed. It is oriented outward from the structure in the direction perpendicular to the impact plane. A peak value as high as $55 \mathrm{~m} / \mathrm{s}^{2}$ was reached during BA-3. A reverse acceleration is also observed,

in a second time. At this measurement point, the acceleration was mainly oriented along the $x$-axis direction. For tests BA-1 and BA-2, the maximum values of the acceleration were three times higher along this axis than that along the $y$ axis. Peak values of the acceleration along the $x$ axis represented $15 \%, 4 \%$, and $4 \%$ of the projectile acceleration peaks for tests 1,2 , and 3 , respectively. A strong attenuation was observed between the first interface (Fig. 8) and the distant plane, with peak values along the $x$ axis in the distant plane of $5 \%, 12 \%$, and $15 \%$ of that at the first interface along the $y$-axis direction for tests 1 to 3 , respectively. This attenuation was significantly higher than between the first interface and the back face in the impact plane (Fig. 8), while both measuring points were at similar distances from the first interface measuring point.

Uplift of the upper part of the structure was observed during the experiments. This was confirmed in Fig. 10, which presents the acceleration along the $z$ axis at 2.5 and 3.5 from the ground and at the second interface. The six curves were characterized by an upward acceleration, over durations as long as $\mathbf{3 0 ~} \mathrm{ms}$ for test BA-3. This peak was followed by a major downward acceleration with maximum amplitude higher than gravity for tests BA-2 and BA-3. The main difference between the two measuring points was a lower peak value measured at $3.5 \mathrm{~m}$ from the ground with a 
Fig. 9. Structure BA. Acceleration in the distant plane at the second interface and $3.5 \mathrm{~m}$ from the ground along the $x$ and $y$ axes ( $a$ and $b$, respectively). [Colour online.]
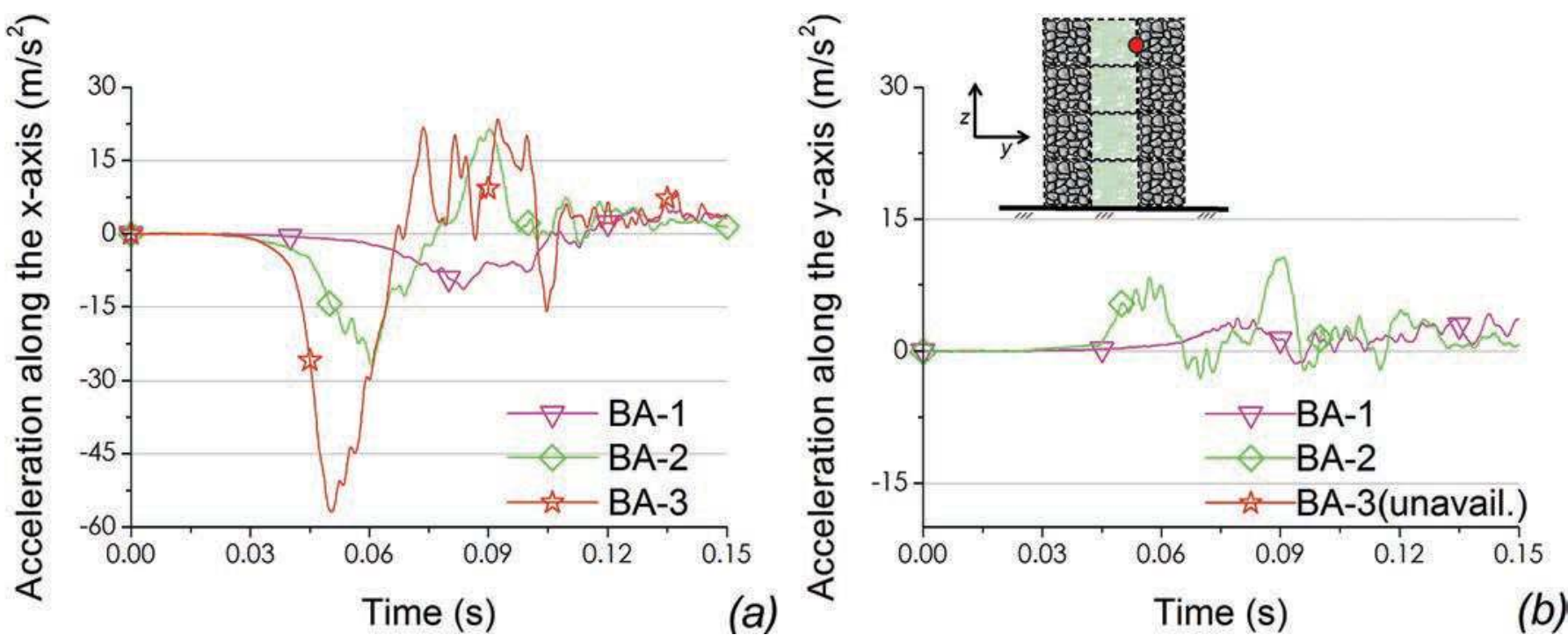

Fig. 10. Structure BA. Acceleration along the $z$ axis in the impact plane and at the second interface, 2.5 and $3.5 \mathrm{~m}$ from the ground ( $a$ and $b$, respectively). [Colour online.]

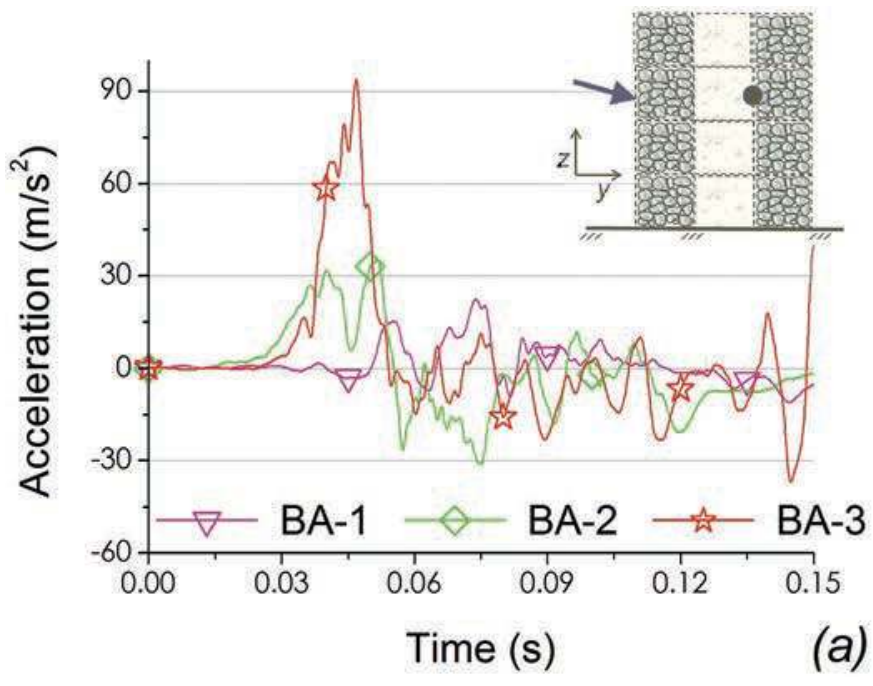

$20 \mathrm{~m} / \mathrm{s}^{2}$ difference in the case of BM-3. The stress wave reached the second interface at a similar time for all three impact tests, about $25 \mathrm{~ms}$ after the impact beginning.

These measurements concerned the interface between the second and third layers of gabions, the accelerometers being attached to the wire mesh. Similar trends and acceleration amplitudes were observed on top of the middle layer of structure BA (Fig. 11, left column). The peak values were very similar to that at the second interface. Nevertheless, longer upward accelerations were observed at the crest, with durations of about $45 \mathrm{~ms}$ compared with $30 \mathrm{~ms}$ at the second interface.

\subsubsection{Difference in response depending on the middle layer fill material}

Figure 11 also shows the difference in response depending on the middle layer fill material. For structure STM, the upward acceleration peak arrived 20 to $35 \mathrm{~ms}$ later and reached a value $25 \%$ to $50 \%$ less than that of structure BA, suggesting different structure uplifts. This really contrasted with the downward acceleration measured $0.5 \mathrm{~m}$ from the structure foundation, in the center

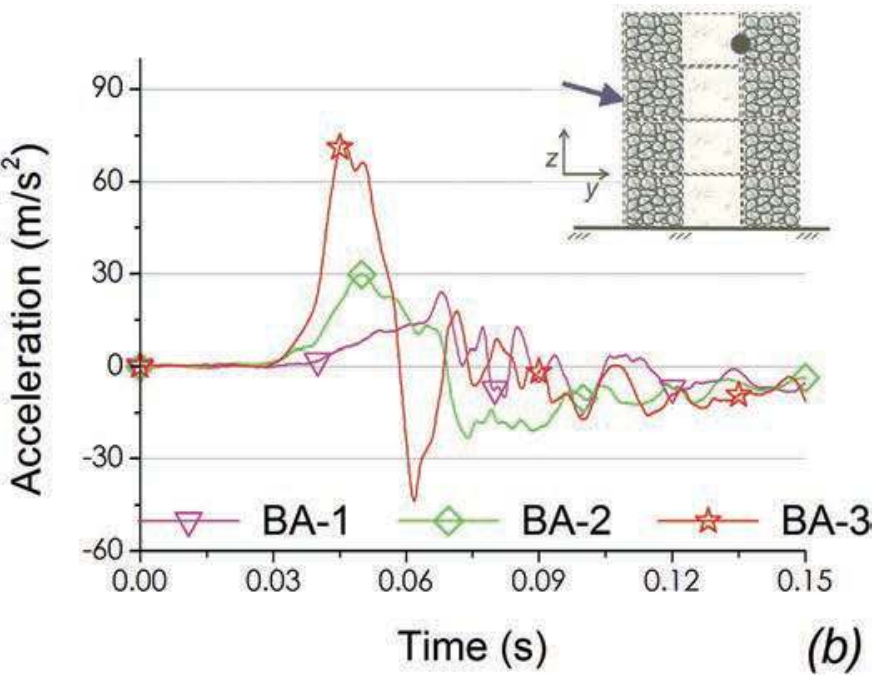

of the middle layer (Fig. 11, right column). While the acceleration at this point was negligible for both structures during the first test, the two other graphs revealed that structure STM experienced higher accelerations close to the foundation, with peak values almost twice that of structure BA for the third test. Note that the curve for test BA-3 is truncated because the signal was lost due to damage to the wire. In addition, the acceleration peak value measured close to the foundation of structure STM during tests 2 and 3 was about 1.7 times that measured at the crest, compared with about 0.7 for structure BA. Finally, the difference in acceleration peak arrival time between the two structures was only $10 \mathrm{~ms}$ compared with $20-35 \mathrm{~ms}$ at the crest. This reveals a strong difference in middle layer response between the two structures as well as different stress evolution patterns during the test series.

The difference in middle layer fill material also affected the acceleration along the $x$ axis (i.e., along the longitudinal axis of the structure) measured in the middle of the middle layer in the distant plane and at $3.5 \mathrm{~m}$ from the ground (Fig. 12). The acceleration 
Fig. 11. Structures BA and STM. Acceleration along the $z$ axis, in the middle of the middle layer in the impact plane, $(a, b$, and $c)$ at the structure crest and $(d, e$, and $f) 0.5 \mathrm{~m}$ from the ground during the three impact tests.
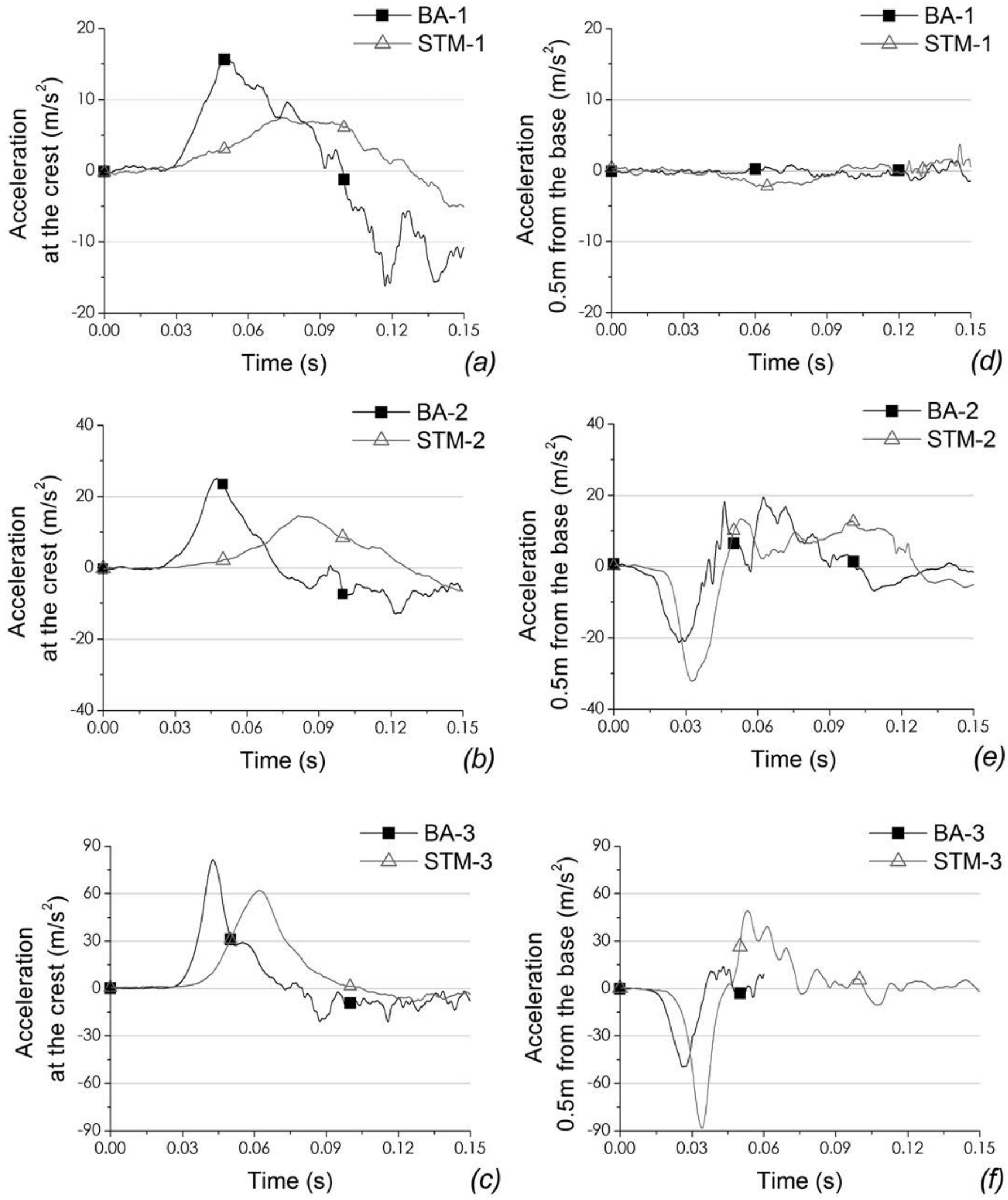
Fig. 12. Structures BA and STM. Acceleration along the $x$ axis in the middle of the middle layer in the distant plane and $3.5 \mathrm{~m}$ from the ground during the second and third impacts tests ( $a$ and $b$, respectively).
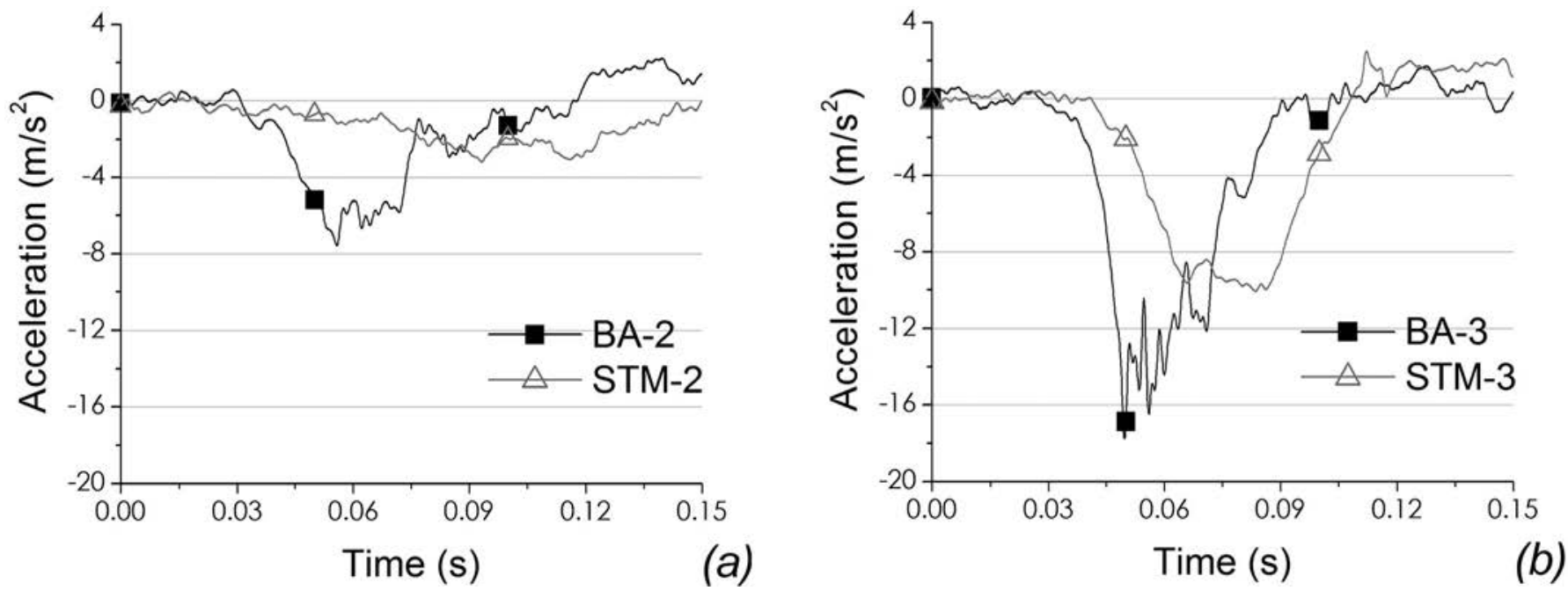

Fig. 13. Evolution of the cross-section of structures $(a)$ BA and (b) STM during the test campaign. The position of the projectile while at rest after the third impact is also shown. [Colour online.]

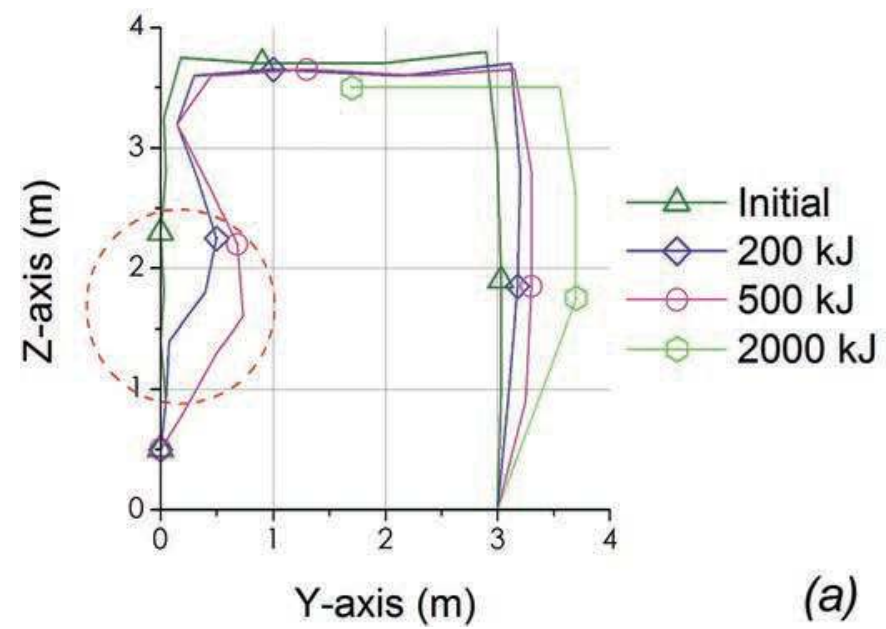

was oriented outward, and a much higher and earlier peak was observed for structure BA. The maximum acceleration was reached during BA-3, with a value of about $17 \mathrm{~m} / \mathrm{s}^{2}$. This value was much less than the $55 \mathrm{~m} / \mathrm{s}^{2}$ peak value measured at the second interface during BA-3, in the distant plane along the same axis (Fig. 9a). This strong difference, while the distance between the two sensors is less than $0.5 \mathrm{~m}$, was attributed to the fact that the latter sensor is connected to the wire mesh at the second interface, separating two layers with different mechanical characteristics.

\subsection{Deformation and displacements}

The deformation of the structure can be tracked based both on the topographical survey of the structure faces after each impact and on the displacement of specific points within the structure during each impact. These latter complement the acceleration measurements for addressing the structure response with time.

\subsubsection{Structure geometry changes}

The topographical survey allowed tracking the changes in structure geometry after each impact. Substantial differences were observed between the two structures, in particular in the impact plane (Fig. 13). For both structures, post-impact bending and crest

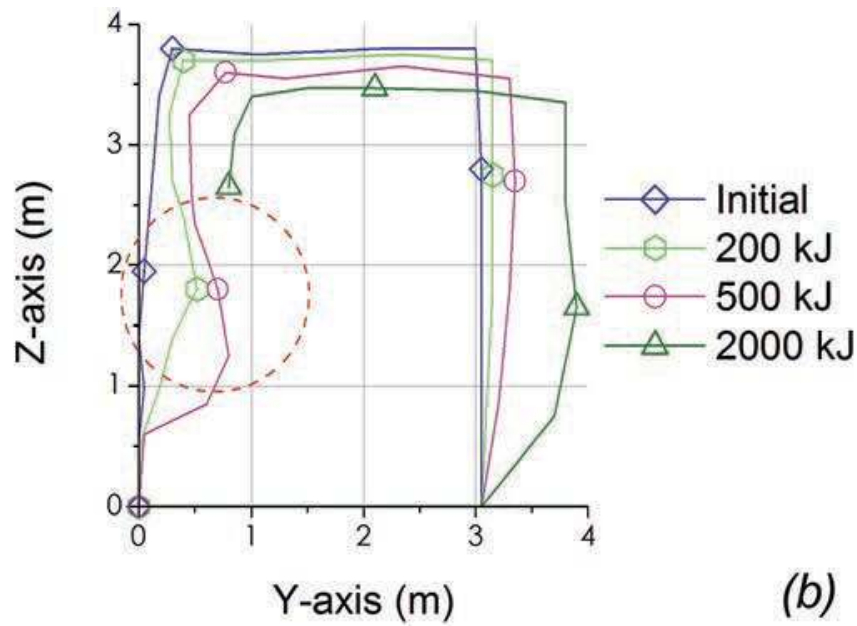

settlement were observed. On the back face, the maximum horizontal displacement after the three tests are $0.2 \mathrm{~m}$ larger for structure STM than for structure BA $(0.9$ vs. $0.7 \mathrm{~m})$. Differences also concern the position of the projectile while at rest and before removal after the third impact, with a penetration $\sim 0.5 \mathrm{~m}$ higher for structure STM than for structure BA. These trends are globally in accordance with observations made in the impact plane by Lambert et al. (2014). On the contrary, in this study, no displacement opposite to the impact direction was observed in the distant plane, $2 \mathrm{~m}$ aside. This difference was attributed to the fact that in this study the structure is freestanding, while in the previous one the structure was leaned against a levee, acting as buttress favoring the reverse displacement of the whole gabion sandwich structure. Differences in deformation from one structure to the other were also observed in the distant plane (results not detailed here). The displacement measured $2 \mathrm{~m}$ from the ground after test 3 was much less for structure BA than for structure STM at the front face ( 0.15 and $35 \mathrm{~m}$, respectively) as well as on the back face ( 0.3 and $0.4 \mathrm{~m}$, respectively).

The displacements within the two structures with time are illustrated focusing on data from three displacement sensors out of five located in the impact plane (Fig. 14). Results for test STM-3 are 
Fig. 14. Displacement with time of three points located in the impact plane during each impact test for structures $(a$ and $b)$ BA and $(c, d$, and e) STM. The location of the three points is shown in the bottom left panel. [Colour online.]
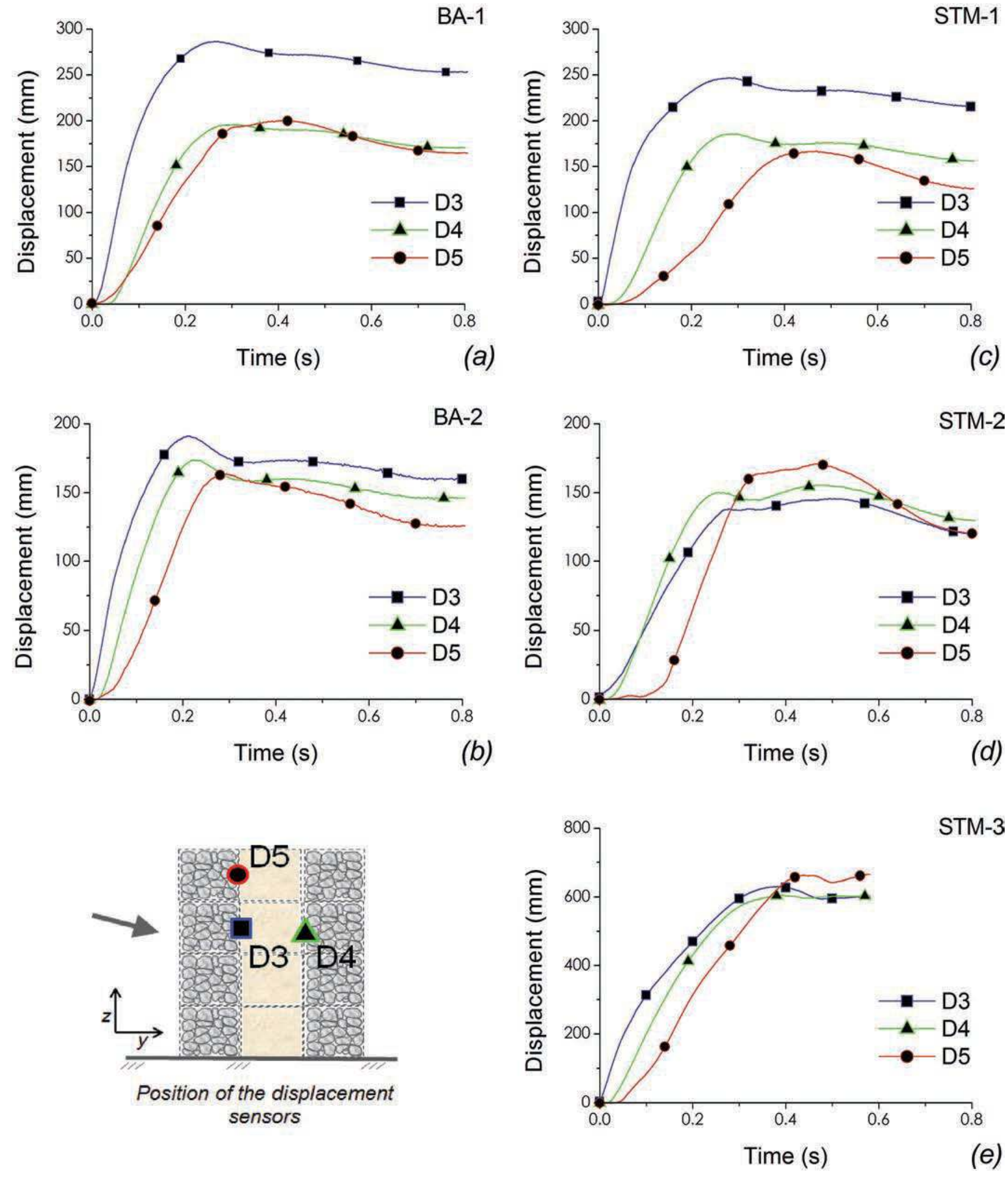
Fig. 15. Middle layer thickness variation during the impact tests for structures (a) BA and (b) STM. [Colour online.]

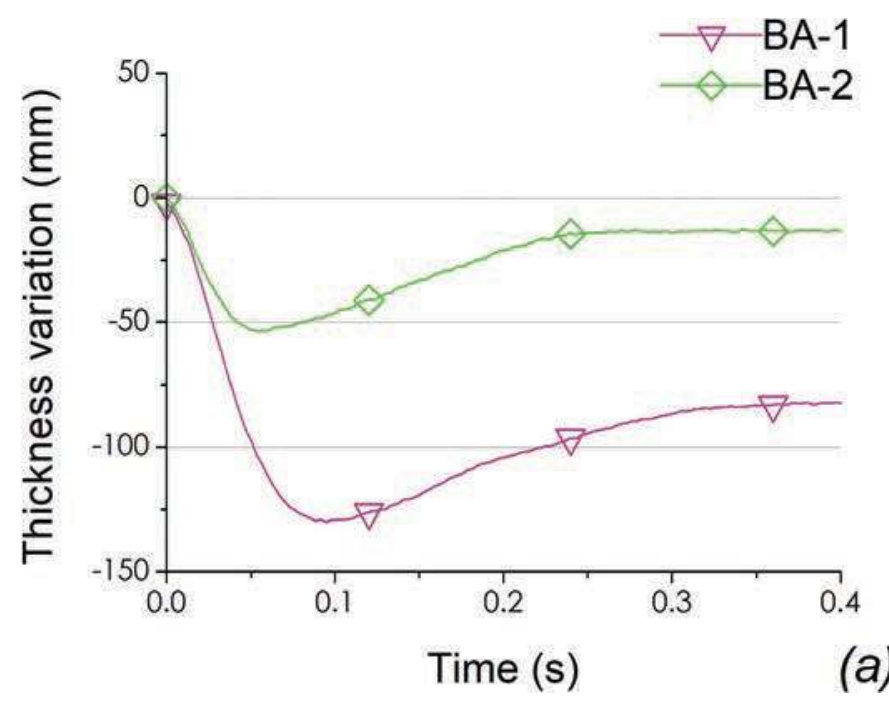

not available. The structures moved for more than $500 \mathrm{~ms}$, much longer than the impact duration (less than $200 \mathrm{~ms}$ ). The time reference considered for plotting the curves is the moment when displacement was detected at D3, the first to experience displacement. D3 was located at the first interface and $2.5 \mathrm{~m}$ from the ground. Point D5, located $1 \mathrm{~m}$ above D3, was always the last to move. For example, the maximum displacement was reached at $t=0.4 \mathrm{~s}$ during BA-1. For both structures, the displacement of D3 was much higher during the first impact than during the second one. The difference in displacement among the three points tended to vanish between test 1 and test 2 . This clearly indicates a global structure displacement during the second test compared with the first test. This is confirmed by the fact that very similar curves are observed during test STM-3 for the three points. A slight reverse displacement was observed for both structures (almost $50 \mathrm{~mm}$ for point D5 during test STM-2).

Using the displacements measured in D3 and D4, it is possible to investigate the middle layer width variation with time at the impact height. Two main conclusions are drawn from Fig. 15. During the first test, the middle layer width decreases down to a minimum value, reached at $t=0.06$ to $0.1 \mathrm{~s}$, depending on the test, followed by a width recovery lasting about $0.2 \mathrm{~s}$. During the second tests a smaller width decrease was observed for structure BA as compared with the first test, and a slight increase was observed for structure STM. The notable difference between the two structures is that the post-peak width recovery during the first impact test was higher for structure STM compared with structure BA ( $50 \%$ vs. $34 \%$, respectively). This difference is attributed to the difference in middle layer fill material characteristics. The recovery is even higher during test STM-3 with a value of $80 \%$. This is in line with the conclusions drawn by Lambert et al. (2014), suggesting the effect of the sand-tire mixture elasticity. Sections 4.3 and 4.4 will discuss these observations in more detail.

Combining data obtained from the topographical survey with those from the displacement sensors made it possible to compare the variation of the width of each of the three layers and in the impact plane when at-rest after the impact (Fig. 16). Plotting these curves until test 3 was not possible due to the severe damages observed in the impacted area, making structure width measurements unreliable at its mid-height. Figures concerning structure BA (left column) revealed that most of the structure width decrease was imputable to the decrease in front face layer width. After the second impact, the front face layer width reduction was $75 \%$ and almost $100 \%$ that of the structure width at 2.5 and $1.5 \mathrm{~m}$ from the ground, respectively. These values reduced to $50 \%$ and

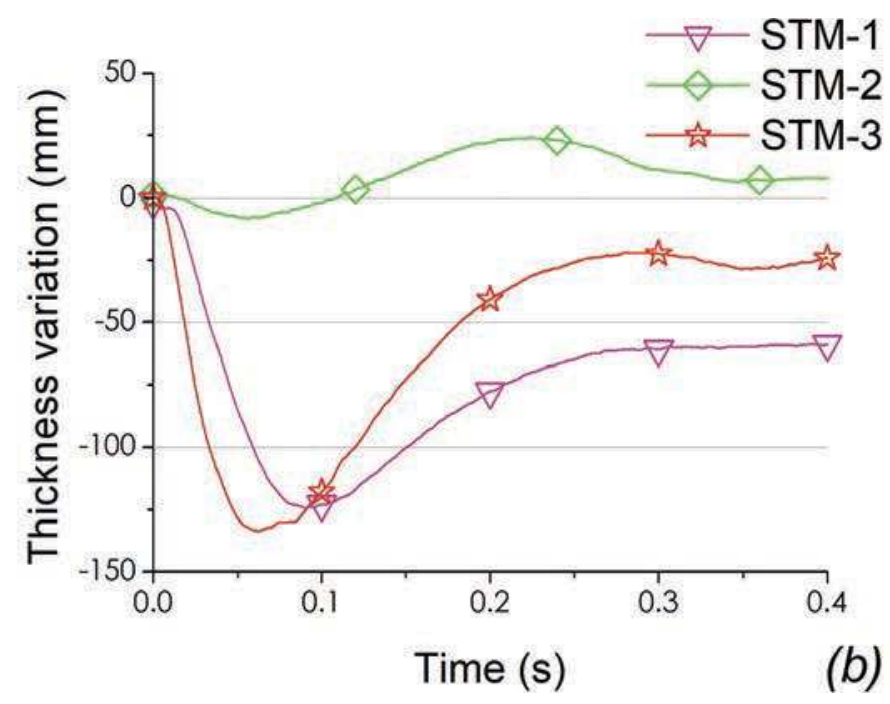

$60 \%$ for structure STM (Fig. 16, right column). The contribution of the middle layer in the structure width decrease was much higher when using the sand-tire mixture as fill material. By contrast, using ballast tended to favor decrease in width of the front layer, associated with damage to the crushed quarry limestone filling this layer. The back layer width of the two structures remained almost constant during the two impact tests.

\section{Discussion}

\subsection{Benefit in using gabions}

The motivation for using gabions for building rockfall protection structures is to erect vertical faces, reducing the structure footprint for an equivalent capacity in terms of rock block kinetic energy. It is worth mentioning that the displacements measured on the back face of the structures during the $2000 \mathrm{~kJ}$ impact test were accounted for by Lambert and Kister (2018) for proposing an expedient efficiency assessment criterion. This criterion is met when, for given impact energy and structure vertical cross-section area, the back face displacement is less than $25 \%$ the mid-height structure width. This impact strength criterion is met with the two tested structures up to $2000 \mathrm{~kJ}$, while these are only $3 \mathrm{~m}$ width at their base. In fact, the efficiency of the studied slender structures is as good as that of embankments of more classical design with similar vertical cross-section area, but having a footprint at least twice higher, considering the average slenderness ratio of existing embankments (Lambert and Kister 2017b).

This efficiency is attributed to another feature derived from the use of gabions. Gabion cages introduce tensile resistance in the structure, in three directions, due to staples interconnecting the gabion mesh panels. This contrasts with other rockfall protection embankments where there is no constitutive material resisting against tensile forces (ground compacted structures) or reinforcement layers offering tensile resistance in two directions only (structures reinforced with geosynthetics, for example). This statement is supported by three observations. Deformed staples on the back facing of the structure clearly indicate that high tensile loads develop in the wire mesh on this face. The wire mesh prevented granular material expulsion, contributing to the structure impact stability. It is noteworthy that while the back face experienced very large displacements, with maximum deflection values up to $0.9 \mathrm{~m}$, no stone ejection was observed from videos of the structure back face. Ejection would have been possible in case of wire breaking, excessive mesh opening, or stone breakage. None of these phenomena were observed on the back 
Fig. 16. Cumulative evolution of the residual thickness of each layer of structures BA (left column) and STM (right column) at 1.5 and $2.5 \mathrm{~m}$ from the ground (bottom and top rows, respectively).

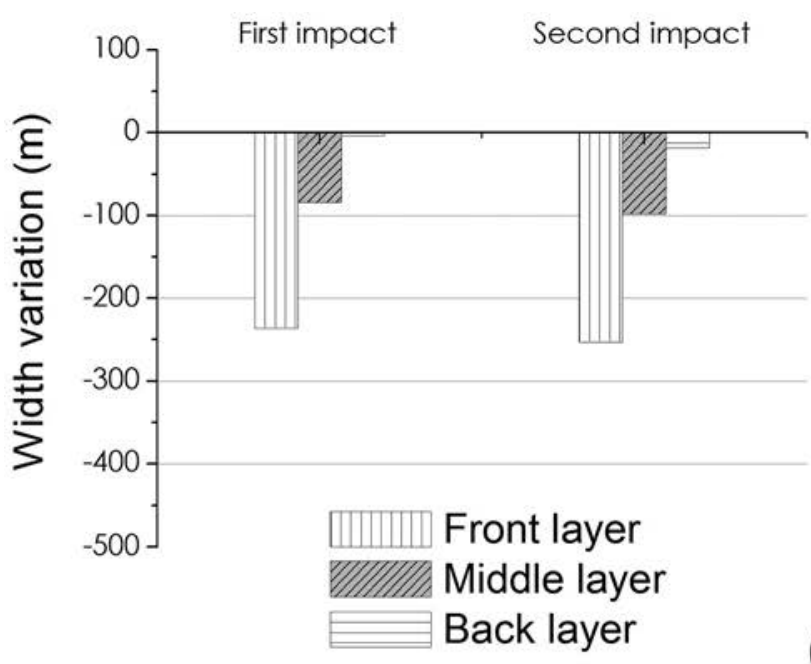

(a)

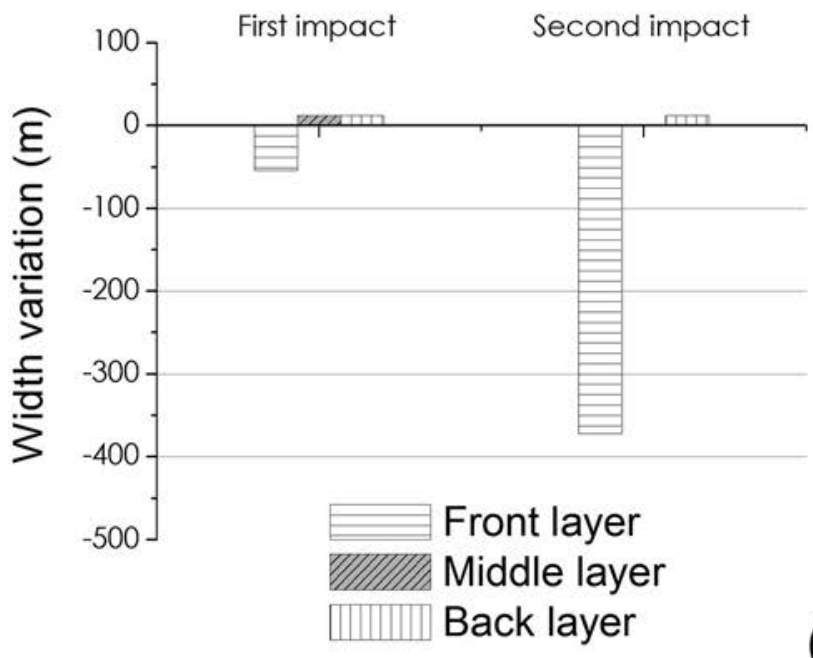

(b)

face of the structure using gabions. This is attributed to the high strain capacity of the double-twisted wire mesh that the gabions were made from. Second, the high-amplitude downward acceleration measured at the second interface and $3.5 \mathrm{~m}$ from the ground in the impact plane (Fig. 10b) suggests a reverse displacement due to the elastic response of the wire mesh. Finally, the displacement observed on point D5, located at the first interface and at a short distance above the impact point, suggests that this interface is pulled via the wire mesh (Fig. 14). Indeed, the fact that the maximum displacement at this point is reached long after the impact ends suggests that this part of the structure is driven by the rest of the structure (namely the middle layer and the back layer) experiencing large displacements.

Overall, these conclusions reveal that the wire mesh tends to increase the zone of the structure associated with the structure impact response. This is the zone enduring large stress and displacement, which is referred to as the impact disturbed zone (IDZ) by Lambert and Kister (2017a). For ground compacted embankments, the IDZ is generally considered to be a truncated cone starting from the impacted zone, with an angle defined as the load spread angle (Ronco et al. 2009). By contrast, with the tested structure, the wire mesh directs the load in all directions increasing the dimensions of the IDZ. Therefore, as the mass of material involved in the structure response increases, so does the structure inertia

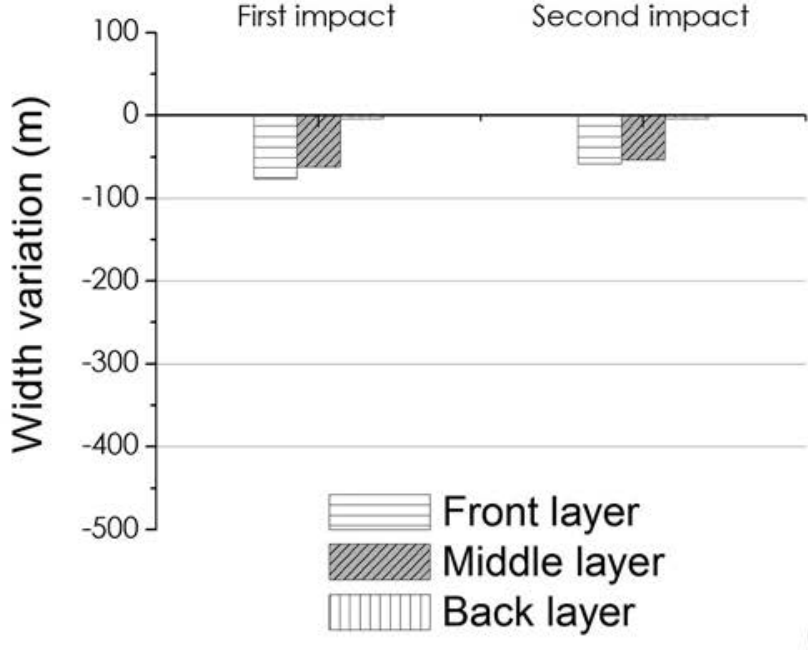

(c)

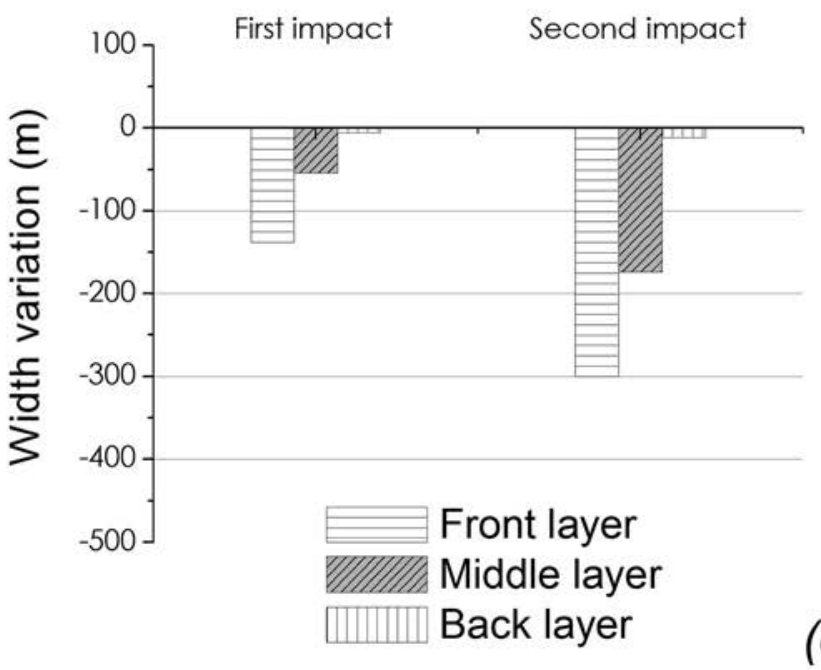

(d)

in particular, with beneficial consequence on its ability in arresting the rock block while experiencing limited displacements. This is in line with observations and comments concerning the effect of the wire mesh reported in Lambert et al. (2014) and demonstrates the beneficial effect of tensile forces on the structure response to impact.

\subsection{Stress wave evolution}

The interaction between the moving projectile and the structure front face generates a high stress gradient that propagates within the structure with time. This wave travels from the impacted area and in all directions and mostly within a typically cone-shaped volume (Ronco et al. 2009). The stress gradient locally induces acceleration of the structure's constitutive materials. Measuring the acceleration in different points in the structure is thus an indirect way to address the way this stress evolves with time and space. This evolution has been shown to be a key issue in the impact strength of rockfall protection embankments, as the displacement it induces may lead to structure collapse if in excess (Lambert and Bourrier 2013; Lambert and Kister 2018).

It is well known that the amplitude of the acceleration at a given point depends on the distance of this point to the stress wave source (impacted area) and on the characteristics of the materials in between. This is particularly true in a semi-finite 
medium and far from the source, where strain remains small. In the presented case, the system dimensions are small, high strains are reached, and the boundary conditions are either rigid, at the structure foundation, or free to deform on the lateral faces and crest. These details are of importance for interpreting the trends deduced from acceleration measurements.

At the structure crest, the acceleration is always higher for structure BA than for structure STM, which would suggest that the amplitude of the incoming stress is higher in the former case (Fig. 11, left column). Nevertheless, the opposite trend is observed at the structure base with higher values measured for structure STM (Fig. 11, right column). As the distance to the wave source and the materials through which the wave travels are similar in both cases (crest and base), similar trends should have been observed, but this is not the case. This discrepancy is attributed to the difference in boundary conditions. On one side, the structure boundary is free to move, while on the other side the structure foundation can be considered rigid. Consequently, a similar incoming stress wave results in different displacements and, thus, accelerations. Conversely, this conclusion shows that acceleration measurements cannot be directly used to address the evolution of the stress wave amplitude with time and space in such a context.

\subsection{Structure response evolution}

The detailed analysis of the displacement measurements allows addressing some facets of the global structure response evolution during the test series. Figure 14 shows that, for both structures, the displacement during the first impact of point D3, at the first interface, is much higher than that at the second interface, in D4. This results in a middle layer width reduction (Fig. 15). The same figure reveals that, by contrast, the displacements during the second impact of these two points are similar. For structure STM, the displacement in D4 slightly exceeds that in D3, resulting in an increased width with respect to the end of the first impact. This observation may appear counterintuitive.

The first point to remember when addressing this issue is that the displacement peaks are all observed long after the stress wave has reached the back face of the structure, that is to say later than $t=0.2 \mathrm{~s}$, while the acceleration is negligible in any point of the structure after $t=0.12 \mathrm{~s}$. Thus, any local displacement measurement later should be interpreted considering that, first, the whole structure is moving, and second, the stress in the structure has substantially decreased. In other words, after $t=0.12 \mathrm{~s}$, there is a decreasing interaction between the layers, and the response of each layer strongly depends on own its kinematics and unloading mechanical response.

Of course, the differences observed between tests 1 and 2 also result from the changes in mechanical characteristics resulting from the first impact, and in particular in the vicinity of the impact, the back layer being marginally concerned. These changes are inherent to experiments consisting of successive impacts. The first impact generates middle layer fill material compaction, associated with its width reduction. The fact that no major middle layer width variation was observed during the second impact is also imputable to differences in fill material pre-impact mechanical characteristics. It is also thought that during the second test, the compression stress generated in the middle layer was insufficiently high as compared with that during the first test for generating additional width reduction, because of a different pattern of stress propagation as mentioned Section 3.3.1.

In the end, it appears that the interpretation of the results presented in Fig. 14 is a complex issue. For instance, the middle layer width variation depends on its mechanical characteristics before impact, the incoming stress, and the displacement of the second interface.

\subsection{Influence of gabion fill material characteristics}

Gabion cages allow using materials with specific characteristics as fill, depending on the gabion position in the structure.

Two middle layer fill materials with very different characteristics have been considered in this study, resulting in substantial differences in structure response. The back face maximal displacement was 30\% larger for structure STM compared with structure BA. For this latter structure, the middle layer exhibited a much larger width reduction together with a larger reverse deformation. By contrast, most of the structure width reduction was localized in the front face layer for structure BA, which is related to crushing. This structure showed higher vertical acceleration peaks in the middle layer at the crest and inversely close to the structure base.

These differences may have different causes related to the middle layer fill materials' mechanical characteristics and behavior. The first parameter to be considered for explaining the lower back face displacement of structure BA is the middle layer fill material unit mass. An increase in unit mass leads to a decrease in structure displacement, due to inertia. The influence of inertia is more pronounced for a freestanding structure than in the case of a structure leaned against a levee or a rigid wall where large displacements are restrained (Heymann 2012; Lambert et al. 2014; Ng et al. 2016).

The second point to consider is the higher lateral spreading of the load in structure BA. This phenomenon is in particular observed at the crest and in the distant plane (Fig. 11, left column; and Fig. 12). It is attributed to the shear resistance of this material, with cohesion and friction angles higher than $60 \mathrm{kPa}$ and 50 degrees, respectively. By contrast, the lower shear characteristics of the sand-tire mixture results in a lower lateral spreading of the load. This means that the volume of structure associated with the impact response is higher for structure BA.

It is worth highlighting that the lateral diffusion with respect to the impact direction does not only result from the linear propagation of the stress wave from the impacted area to the considered point. A high-amplitude, vertically oriented acceleration has been observed in the impact plane at the second interface (Fig. 10). In addition, the acceleration was mainly oriented along the $x$ axis in the aside plane (Fig. 9), that is to say along the longitudinal axis of the structure. These two observations may be interpreted as the consequence of the lateral expansion of fill materials located in the impact direction, in the impact plane. Indeed, materials at structure mid-height in the impact plane experience high stress in the impact direction, resulting in expansion in directions perpendicular to this loading axis. This mechanism explains the two observations above and contributes to the lateral diffusion of the load within the structure.

The higher middle layer unit mass and load spreading capacity of structure BA, together with its assumed higher elastic modulus, result in a higher apparent modulus at the first interface than for structure STM. Consequently, a higher stress develops between the projectile and this interface, that is to say in the first gabion layer. Crushed quarry limestone was selected as front face gabions fill material to derive benefit from the crushing of this material during impact. Crushing first contributes in dissipating the strain energy stored in the stones reached by the stress wave. Second, crushing limits the stress transmitted inward into the structure, to an extent inversely proportional to the stones' crushing strength (Lambert et al. 2009; Bourrier et al. 2011; Ng et al. 2018). A major crushing was observed for both structures, at higher impact energies notably. This effect was more pronounced for structure BA, as deduced from the front layer width evolution (Fig. 16). The difference in apparent modulus at the first interface explains this difference. The same conclusion was drawn based on halfscale experiments conducted on a two-layered gabion wall leaned against a rigid wall (Heymann 2012). In this latter case, ballast used as second layer fill material led to a high concentration of 
deformation in the first layer of gabions, filled with crushed quarry limestone, while $30 \%$ of the deformation occurred in the second layer when filled with a sand-tire mixture.

\subsection{Applications}

This study has detailed the response of very specific freestanding structures, based on a large number of measurements. It is not recommended to generalize these results to other structure types such as classical embankments or granular cushion layers protecting rigid structures (see for example Ng et al. 2016 or Su et al. 2019). This in particular concerns the use of the measured projectile acceleration in view of deriving the impact force, which is a general practice for designing structures. The projectile acceleration during impact is highly dependent on the structure mechanical characteristics.

The results were deliberately not compared with values obtained from the theoretical equations proposed in the literature pertaining to rockfall protection embankments for computing impact loads. These equations have been shown to provide scattered results with impact forces in a ratio of 1 to 4 for a similar situation (see Lambert and Kister 2017a). Moreover, the presented results confirmed that the projectile acceleration, and thus impact force, is clearly insufficient for addressing the structure impact response. For instance, the same peak value of projectile acceleration resulted in different structure displacement and deformation.

On a practical point of view, it is worth raising the influence of the data treatment on the acceleration peak value. Smoothing the raw signal to get an interpretable acceleration curve may have a strong influence on the peak value. The difference in peak value between two apparently appropriate filtering methods was found to be as high as $20 \%$, questioning the reliability of the impact force deduced from this acceleration peak.

The comparative study between the two structures revealed that ballast used as middle layer fill material improved the structure impact response. Because of its higher unit mass and shear strength, ballast increased crushing in the front gabion layer and reduced the displacement of the structure back face. This conclusion concerns freestanding structures and may be not be valid for granular cushion layers protecting rigid walls. For example, Heymann et al. (2010) conducted impact experiments on twolayered sandwich gabion structures and concluded that ballast was less efficient than a sand-tire mixture in reducing the dynamic load transmitted to the wall on which the structure was leaning. This difference in conclusion is attributed to the difference in boundary conditions, which has an influence on the mechanisms with influence on the structure impact response. For example, inertia is less important and less influential in the case of a structure leaning against a rigid wall.

\section{Conclusion}

This article has presented real-scale impact experiments on two different three-layered sandwich structures made of gabions, $4 \mathrm{~m}$ in height and 1.3 in slenderness ratio. The experiments proved this technology efficient for intercepting rockfall with kinetic energy of at least $2000 \mathrm{~kJ}$. For such an impact energy, the back face displacement was less than $0.9 \mathrm{~m}$. The experiments have also demonstrated that using ballast as middle layer fill material improves the structure response in terms of back face deformation.

Measurements made during the experiments provided a set of experimental data of great value for investigating the response of these structures. The experiments have highlighted the influence of the wire mesh and fill materials characteristics. The wire mesh prevents excessive back face displacement. It also contributes in increasing the structure volume associated to the impact response. As for the middle layer fill material characteristics, this study has brought evidence on the beneficial influence of the unit mass and shear strength. The fill material elasticity and lateral expansion of the fill material has also been shown to influence the structure response. Ballast has been shown to favor crushing in the front gabion layer and to contribute in the increase of the structure volume associated to the structure response.

Overall, the observations made illustrate both the composite and sandwich natures of these layered gabion structures. The composite nature is revealed by the interaction between the gabion cages and the fill material. The sandwich nature is revealed by the influence of the characteristics of one layer on the response of the other, for example a higher crushing is observed in the front layer when using ballast for a middle layer fill material.

In addition to revealing the complexity of the structure response to impact, these experiments are of interest for developing numerical models such as those proposed by Ronco et al. (2009) or Breugnot et al. (2015). It provides a set of data to be used for validation purpose and draws the attention on which phenomenon the model should be able to reproduce and on the related parameters required for a precise calibration.

\section{Acknowledgements}

This study was part of the research project REMPARe, funded by the French national research agency (ANR). The authors thank all the partners and in particular Géolithe, Céréma, and Razel. The authors warmly commend Adeline Heymann, whose doctoral work served as a basis for this article.

\section{References}

Amato, G., O’Brien, F., Simms, C.K., and Ghosh, B. 2015. Gabions: evaluation of potential as low-cost roadside barriers. International Journal of Crashworthiness, 20(1): 12-26. doi:10.1080/13588265.2014.949038.

Bourrier, F., Lambert, S., Heymann, A., Gotteland, P., and Nicot, F. 2011. How multi-scale approaches can benefit the design of cellular rockfall protection structures. Canadian Geotechnical Journal, 48(12): 1803-1816. doi:10.1139/t11072 .

Breugnot, A., Lambert, S., Villard, P., and Gotteland, P. 2015. A discrete/continuous coupled approach for modeling impacts on cellular geostructures. Rock Mechanics and Rock Engineering, 49(5): 1831-1848. doi:10.1007/s00603-0150886-8.

Edeskär, T. 2004. Technical and environmental properties of tyre shreds focusing on ground engineering applications. Luleä University of technology.

Hennebert, P., Lambert, S., Fouillen, F., and Charrasse, B. 2014. Assessing the environmental impact of shredded tires as embankment fill material. Canadian Geotechnical Journal, 51(5): 469-478. doi:10.1139/cgj-2013-0194.

Heymann, A. 2012. Approche expérimentale du comportement mécanique des géo-ouvrages à technologie cellulaire. Application aux ouvrages pare-blocs. Doctoral thesis, University Joseph Fourier, Grenoble, France. [In French.].

Heymann, A., Lambert, S., Haza-Rozier, E., Vinceslas, G., and Gotteland, P. 2010. An experimental comparison of half-scale rockfall protection sandwich structures. In Proceedings of the 11th International Conference on Structures Under Shock and Impact, Tallinn, Estonia, 28-30 July 2010. pp. 15-26.

Lambert, S., and Bourrier, F. 2013. Design of rockfall protection embankments: A review. Engineering Geology, 154: 77-88. doi:10.1016/j.enggeo.2012.12.012.

Lambert, S., and Kister, B. 2017a. Analysis of Existing Rockfall Embankments of Switzerland (AERES); Part A: State of Knowledge [online]. Federal Office for the Environment, Bern. Available from https://www.bafu.admin.ch [accessed 10 October 2019].

Lambert, S., and Kister, B. 2017b. Analysis of Existing Rockfall Embankments of Switzerland (AERES); Part B: analysis of the collected data and comparison with up-to-date knowledge [online]. Federal Office for the Environment, Bern. Available from https://www.bafu.admin.ch [accessed 10 Ocober 2019].

Lambert, S., and Kister, B. 2018. Efficiency assessment of existing rockfall protection embankments based on an impact strength criterion. Engineering Geology, 243: 1-9. doi:10.1016/j.enggeo.2018.06.008.

Lambert, S., Gotteland, P., and Nicot, F. 2009. Experimental study of the impact response of geocells as components of rockfall protection embankments. Natural Hazards and Earth Systems Science, 9: 459-467. doi:10.5194/nhess-9459-2009.

Lambert, S., Heymann, A., Gotteland, P., and Nicot, F. 2014. Real-scale investigation of the kinematic response of a rockfall protection embankment. Natural Hazards and Earth Systems Science, 14: 1269-1281. doi:10.5194/nhess-14-12692014.

Lee, H.J., and Roh, H.S. 2007. The use of recycled tire chips to minimize dynamic earth pressure during compaction of backfill. Construction and Building Materials, 21(5): 1016-1026. doi:10.1016/j.conbuildmat.2006.02.003.

Lorentz, J., Plassiard, J.-P., and Muquet, L. 2010. An innovative design process for rockfall embankments: application in the protection of a building at Val d'Isère. In Proceedings of the 3rd Euro-Mediterranean Symposium on ad- 
vances in Geomaterials and Structures, Djerba, Tunisia, May 2010. pp. 277-282.

Ng, C.W.W., Choi, C.E., Su, A.Y., Kwan, J.S.H., and Lam, C. 2016. Large-scale successive boulder impacts on a rigid barrier shielded by gabions. Canadian Geotechnical Journal, 53(10): 1688-1699. doi:10.1139/cgj-2016-0073.

Ng, C.W.W., Su, A.Y., Choi, C.E., Song, D., Lam, C., Kwan, J.S.H., et al. 2018. Comparison of cushioning mechanisms between cellular glass and gabions subjected to successive boulder impacts. Journal of Geotechnical and Geoenvironmental Engineering, 144(9). 04018058. doi:10.1061/(ASCE)GT.1943-5606. 0001922.

Ronco, C., Oggeri, C., and Peila, D. 2009. Design of reinforced ground embankments used for rockfall protection. Natural Hazards and Earth System Sciences, 9: 1189-1199. doi:10.5194/nhess-9-1189-2009.
Simmons, M., Pollak, S., and Peirone, B. 2009. High-energy rock fall embankment constructed using a freestanding woven wire mesh reinforced soil structure. In Proceedings of the 60th Highway Geology Symposium. 29 September - 1 October 2009. Buffalo, New York. pp. 290-301.

Su, Y., Choi, C.E., Ng, C.W.W., Lam, C., Kwan, J.S.H., and Wu, G. 2018. Eco-friendly recycled crushed glass for cushioning boulder impacts. Canadian Geotechnical Journal, 56(9): 1251-1260. doi:10.1139/cgj-2018-0200.

Su, Y., Cui, Y., Ng, C.W.W., Choi, C.E., and Kwan, J.S.H. 2019. Effects of particle size and cushioning thickness on the performance of rock-filled gabions used in protection against boulder impact. Canadian Geotechnical Journal, 56(2): 198-207. doi:10.1139/cgj-2017-0370.

Zornberg, J., Cabral, A., and Viratjandra, C. 2004. Behaviour of tire shred-sand mixtures. Canadian Geotechnical Journal, 41(2): 227-241. doi:10.1139/t03-086. 